05,12

\title{
Магнитные наночастицы, полученные электрофизическими методами: фокус на биомедицинские приложения
}

\author{
(ㄷ Г.В. Курляндская ${ }^{1,2}$, А.П. Сафрронов ${ }^{1,3}$, С.В. Щербинин ${ }^{1,3}$, И.В. Бекетов ${ }^{1,3}$, \\ Ф.А. Бляхман ${ }^{1,4}$, Э.Б. Макарова ${ }^{4,5}$, М.А. Корч $^{6}$, А.В. Свалов ${ }^{1}$ \\ ${ }^{1}$ Уральский федеральный университет, \\ Екатеринбург, Россия \\ ${ }^{2}$ University of the Basque Country UPV-EHU, Department of Electricity and Electronics, \\ Barrio Sarriena s/n, Leioa, 48940, Spain \\ ${ }^{3}$ Институт электрофизики РАН, \\ Екатеринбург, Россия \\ ${ }^{4}$ Уральский государственный медицинский университет, \\ Екатеринбург, Россия \\ ${ }^{5}$ Уральский институт травматологии и ортопедии, \\ Екатеринбург, Россия \\ ${ }^{6}$ Уральский государственный аграрный университет, \\ Екатеринбург, Россия \\ E-mail: galinakurlyandskaya@urfu.ru
}

Поступила в Редакцию 9 апреля 2021 г.

В окончательной редакции 9 апреля 2021 г.

Принята к публикации 19 апреля 2021 г.

Рассмотрены возможности получения больших партий магнитных наночастиц (МНЧ) с помощью электрофизических методов электрического взрыва проволоки, лазерного испарения мишени и искрового разряда. Биоприложения МНЧ требуют получения магнитных материалов в виде стабилизированных водных суспензий или гидрогелей с магнитными наполнителями, поэтому обсуждаются некоторые детали синтеза этих материалов и их аттестации. Рассмотрены вопросы взаимодействия МНЧ с биологическими системами, проблема биосовместимости, возможность использования субстратов феррогелей для нужд клеточных технологий и регенеративной медицины, а также в качестве биомиметиков при создании магнитных биосенсоров. Приведены результаты анализа ряда различных биологических экспериментов, проведенных с суспензиями различного типа, полученных на основе одной и той же партии МНЧ. Анализ примеров магнитного биодетектирования и существующих теоретических подходов позволит оценить перспективы данного научного направления для создания высокочувствительных пленочных сенсоров на основе гигантского магнитоимпедансного эффекта для биомедицинских приложений.

Ключевые слова: магнитные наночастицы, оксиды железа, феррогели, электрический взрыв проволоки, лазерное испарение, метод искрового разряда, пленочные наноструктуры, детекторы слабых магнитных полей, магнитный импеданс, биоприложения.

DOI: $10.21883 /$ FTT.2021.09.51255.17H

\section{1. Введение}

В середине прошлого столетия на стыке коллоидной химии и физики металлов возникла область научного знания, ставящая своей задачей исследование макроскопических ансамблей малых частиц, размеры которых лежат в области $1-100 \mathrm{~nm}$, физика ультрадисперсных сред [1]. Указанный интервал включает размеры, соответствующие размерам ряда вирусов (от 2 до $400 \mathrm{~nm}$ ), белков (от 5 до $50 \mathrm{~nm}$ ) и геометрическим параметрам генов (ширина $2 \mathrm{~nm}$ и длина от 10 до $100 \mathrm{~nm}$ ) [2], обеспечивая хорошую размерную совместимость. Под наночастицей принято понимать частицу, в которой число атомов, расположенных в объеме, превышает не более чем на два порядка число атомов, находящихся на поверхности. Особый интерес вызывают разнооб- разные биомедицинские приложения магнитных наночастиц (МНЧ).

Наиболее широко с точки зрения биомедицинских приложений изучаются МНЧ магнетита $\left(\mathrm{Fe}_{3} \mathrm{O}_{4}\right)$ и маггемита $\left(\gamma-\mathrm{Fe}_{2} \mathrm{O}_{3}\right)$ [3-6]. Это связано с меньшей токсичностью наночастиц оксидов железа в сравнении с чистыми металлами и большинством магнитных сплавов [7,8]. Несмотря на значительный прогресс методов получения магнитных наночастиц, в отличие от небольших молекул, имеющих определенные химические формулы, МНЧ различаются по количеству и расположению составляющих их атомов, даже в случае ансамбля наночастиц одной партии, что определяет вариабельность их физических и химических параметров. Однако биоприложения наноматериалов требуют синтеза больших партий МНЧ, т.к. для аттестации используется расширенный набор экспериментальных техник, и каждая партия 
препаратов, содержащих МНЧ, перед непосредственным использованием требует дополнительной проверки [9]. Таким образом, только большие партии наночастиц имеют перспективы использования в качестве фармакологических нанопрепаратов. Кроме того, в случае большого размера партии МНЧ, на основе одной и той же партии могут быть получены водные суспензии различного типа (получение устойчивых водных суспензий - необходимое условие биоприложений) и проведены эксперименты на разных биологических объектах, т.е. обеспечена возможность адекватного сравнения результатов. Строго говоря, сравнение данных биологических экспериментов для частиц различных партий может вносить заметные погрешности в результаты экспериментов.

Статистические данные говорят о том, что около $92 \%$ МНЧ оксидов железа получают химическими, 6\% физическими и $2 \%$ - биологическими методами синтеза $[10,11]$. При этом именно методы физического синтеза МНЧ, обеспечивающие получение больших партий наночастиц, востребованных в биомедицине, вызывают специальный интерес в последние годы.

Приложения МНЧ в медицине многочисленны: магнитно-резонансная томография, магнитная гипертермия и термическая абляция, магнитные таргетная терапия и доставка лекарств, магнитная сепарация, релаксометрия, регенеративная медицина, магнитное биодетектирование и др. [12-16]. Особое внимание в последние годы уделялось направлению, ориентированному на механизмы магнитомеханической терапии [15-18]. Хотя наибольшее количество работ было выполнено с использованием магнитных нанодисков с магнитными вихрями, полученных на основе пленочных структур $[18,19]$, очевидно, что магнитные нанопроволоки [20] и наночастицы с высокой магнитострикцией [21] следует рассматривать как перспективные материалы для магнитомеханической терапии.

В настоящей работе подробно рассмотрены возможности получения больших партий МНЧ с помощью электрофизических методов электрического взрыва проволоки (ЭВП) [22-24], лазерного испарения мишени (ЛИМ) [25,26] и искрового разряда (ИР) [27-28] и предложены новые направления их биомедицинских приложений. Все использованные авторами наночастицы были получены в лаборатории импульсных процессов Института электрофизики УрО РАН [29]. Работа не претендует на полноту описания всех существующих электрофизических методов получения МНЧ и методов их аттестации. В большей степени она носит обзорный характер и ориентирована на сравнительный анализ результатов авторов, полученных в последнее десятилетие. Поскольку МНЧ получаются и исследуются с одних и тех же методологических позиций, часто с использованием одних и тех же инструментов, степень достоверности сравнительного анализа значительно повышается. Некоторые исследования были выполнены в рамках сотрудничества с другими группами, и они затрагивают лишь очень частные вопросы. В других случаях полученные и аттестованные нами наночастицы были переданы для независимых исследований другим коллективам, и наконец, просто в целях сравнения и понимания места МНЧ, полученных электрофизическими методами, с МНЧ другого типа нам приходилось сопоставлять данные различных исследователей.

Поскольку биоприложения МНЧ требуют получения магнитных материалов в виде стабилизированных водных суспензий или гидрогелей с магнитными наполнителями, мы упомянем некоторые детали синтеза этих материалов, включая обсуждение современных методов аттестации [30-33]. Далее будут затронуты отдельные вопросы взаимодействия МНЧ с биологическими системами. Мы обсудим возможность использования феррогелей в качестве субстратов в клеточных технологиях и регенеративной медицине, а также как биомиметиков при создании магнитных биосенсоров на основе сенсоров слабых магнитных полей. Анализ примеров магнитного биодетектирования $[13,27]$ позволит оценить перспективы создания пленочных детекторов на основе гигантского магнитоимпедансного эффекта (ГМИ) $[31,33]$ для биоприложений.

Таким образом, в работе сравнительно анализируются особенности синтеза и свойства больших партий магнитных наночастиц, полученных с помощью электрофизических методов электрического взрыва проволоки, лазерного испарения мишени и искрового разряда, в контексте новых направлений их биомедицинских приложений.

\section{2. Получение магнитных наночастиц электрофизическими методами и некоторые их характеристики}

Метод электрического взрыва проволоки был использован для получения МНЧ оксида железа в Институте электрофизики РАН ( Екатеринбург, Россия). Для синтеза наночастиц оксида железа использовалась железная проволока марки Ст3 диаметром $0.47 \mathrm{~mm}$ с содержанием углерода 0.09\%. Подробно экспериментальная ЭВП-установка описана в работах [22-24]. Кратко процесс ЭВП можно описать так. Проволока требуемого состава, предварительно намотанная на катушку, выпрямляется и непрерывно подается механизмом подачи во взрывную камеру через втулку с уплотнением. Внутри взрывной камеры проволока размещается между верхним (заземленным) и нижним (высоковольтным) электродами, подключенными через управляемый искровой разрядник к емкостному накопителю (ЕН) генератора импульсных токов, который заряжается до заданного напряжения после каждого взрыва. Когда конец проволоки достигает нижнего высоковольтного электрода, происходит разряд $\mathrm{EH}$, и протекающий через отрезок проволоки импульс электрического тока испаряет его. Проволока подается во взрывную камеру непрерывно, и процесс повторяется снова. Синтез наночастиц оксида железа 


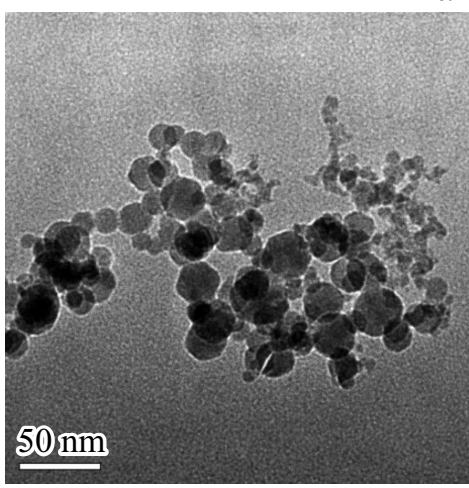

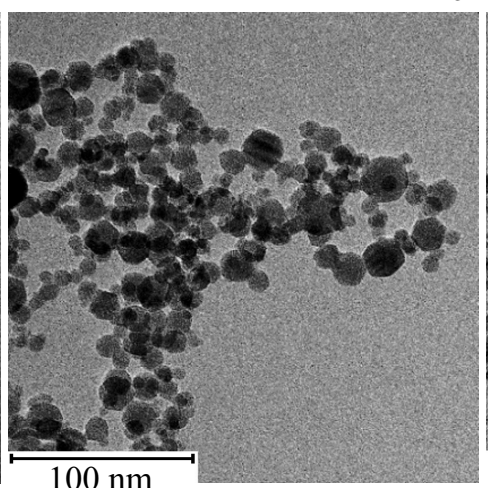

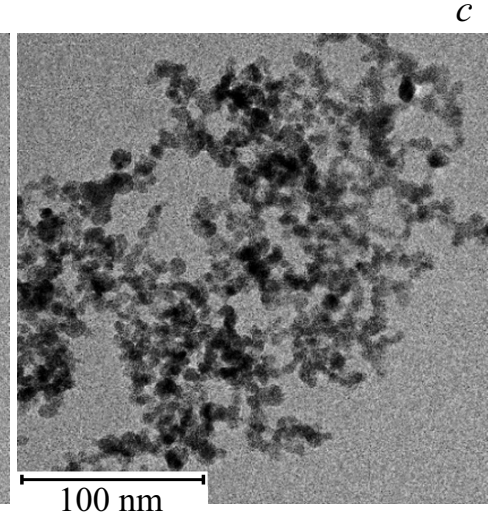

Рис. 1. Магнитные наночастицы $\mathrm{Fe}_{x} \mathrm{O}_{y}$, полученные электрофизическими методами: $a$ ) электрического взрыва проволоки (поле зрения $-280 \times 280 \mathrm{~nm}), b)$ лазерного испарения мишени (поле зрения $-260 \times 260 \mathrm{~nm})$, и $c$ ) искрового разряда (поле зрения $260 \times 260 \mathrm{~nm})$. Просвечивающая электронная микроскопия.

происходит в газовой смеси, содержащей $80 \%$ азота и $20 \%$ кислорода. Наличие последнего обеспечивает получение именно оксидов железа. Как правило, порошок состоит их двух кристаллографических фаз, магнетита и гематита $\left(\alpha-\mathrm{Fe}_{2} \mathrm{O}_{3}\right)$, в процентном соотношении 90:10, которое зависит от технологических параметров конкретного процесса синтеза.

Газовая система установки ЭВП содержит устройства сепарации инерционного типа. Это позволяет разделять образующиеся в результате ЭВП частицы на различные размерные фракции: так, фракции циклона соответствует средний диаметр сферических частиц $22 \mathrm{~nm}$, а фракции

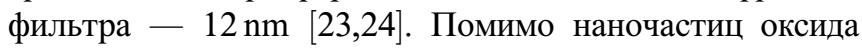
железа (рис. 1, $a$ ), метод ЭВП позволяет синтезировать наночастицы металлов ( $\mathrm{Cu}, \mathrm{Al}, \mathrm{Ag}, \mathrm{Ni}, \mathrm{W}, \mathrm{Co}$ и др.), сплавов (FeNi, $\mathrm{FeCo}, \mathrm{AlMg}, \mathrm{CuNi}$ и др.), а также их химических соединений (оксиды, нитриды, карбиды металлов).

ЭВП в случае МНЧ оксида железа позволяет получать большие партии до $200 \mathrm{~g}$ порошка в час. Кроме сравнительно высокой производительности (до $500 \mathrm{gph}$ ), метод ЭВП отличается от других методов низким энергопотреблением (около $25 \mathrm{kWt} \cdot \mathrm{hour} / \mathrm{kg}$ ) и обеспечивает получение слабоагрегированных наночастиц сферической формы. Очень высокая степень приближения к сферической форме, подтвержденная не только визуальными исследованиями, но магнитными и микроволновыми методиками работах $[23,24]$ - дополнительное достоинство электрофизических методов.

В настоящее время наиболее широко используемый электрофизический метод получения сферических МНЧ - это метод высокотемпературного физического диспергирования на основе испарения лазерным лучом (ЛИМ) с последующей конденсацией паров в газовой фазе $[25,26]$. Для получения МНЧ оксида железа использовалась лабораторная установка с волоконным иттербиевым (Yb) лазером с длиной волны $1.07 \mu \mathrm{m}$. Мишень диаметром $65 \mathrm{~mm}$ прессовалась из коммерческих микрочастиц магнетита $\left(\mathrm{Fe}_{3} \mathrm{O}_{4}\right)$, она была установлена в испарительной камере на приводном механизме, что обеспечивало ее вращение и горизонтальное перемещение. Луч импульсного лазера фокусировался на поверхности мишени с помощью оптической системы с фокусным расстоянием $200 \mathrm{~mm}$. Диаметр фокального пятна составлял $0.45 \mathrm{~mm}$. Скорость сканирования луча $-20 \mathrm{~cm} / \mathrm{s}$, частота импульсов $-4.85 \mathrm{kHz}$, и длительность импульса - $60 \mu \mathrm{s}$. ЛИМ в случае наночастиц оксида железа позволяет получать сравнительно большие партии до $50 \mathrm{~g}$ порошка в час. Средний типичный диаметр сферических частиц ЛИМ (рис. $1, b)$ составляет около $10 \mathrm{~nm}[20,21]$, т. е. несколько меньше, чем в случае ЭВП. ЛИМ МНЧ, полученные в оптимальных условиях, однофазны: постоянная решетки кристаллической фазы оказывается значительно ниже, чем у стехиометрического магнетита $\mathrm{Fe}_{3} \mathrm{O}_{4}$, но несколько выше, чем постоянная решетки маггемита $\gamma-\mathrm{Fe}_{2} \mathrm{O}_{3}$.

Основы метода искрового разряда были разработаны уже в конце 80-х гг. прошлого века [28], но в настоящее время появилась возможность использовать искровые генераторы с рабочим циклом порядка микросекунд, зарядными напряжениями накопительного конденсатора до $25 \mathrm{kV}$ и энергиями, запасаемыми емкостным накопителем, в десятки $J$ [27]. В настоящей работе для получения наночастиц оксида железа искровой разряд (ИР) осуществлялся между двумя параллельно расположенными цилиндрическими электродами из низкоуглеродистой стали. В качестве накопителя энергии использовался один импульсный конденсатор типа ИК-100 емкостью $0.25 \mu \mathrm{F}$. Разряд конденсатора через зазор инициировался подачей триггерного импульса амплитудой $20 \mathrm{kV}$ и длительностью $200 \mathrm{~ns}$ на управляющий электрод, расположенный в разрядном промежутке. Получаемый материал содержит три типа наночастиц: гематит (5-8\%) и мелкую (около 80-85\%) и крупную $(9-10 \%)$ фракции магнетита. Средний диаметр мелкой фракции магнетита, представляющей собой сферические 


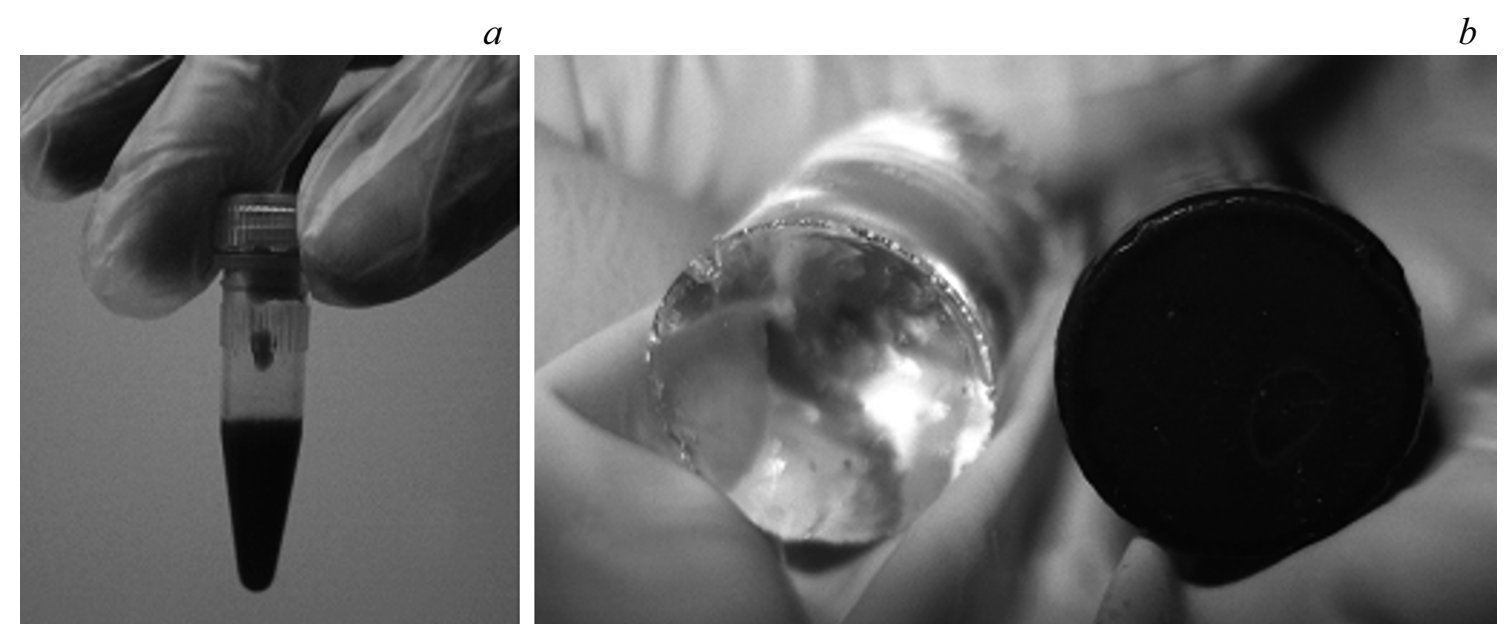

Рис. 2. Внешний вид: $a)$ стабилизированной в водной среде суспензии ЛИМ-наночастиц маггемита $\left(\gamma\right.$ - $\left.\left.\mathrm{Fe}_{2} \mathrm{O}_{3}\right) ; b\right)$ гидрогель (прозрачный) и феррогель на основе акриламида, полученный с использованием стабилизированной водной суспензии ЛИМ-наночастиц маггемита (концентрация МНЧ оксида железа составляет $4.0 \mathrm{wt} \%$ ).

частицы, составляет около $7 \mathrm{~nm}$ (рис. 1,b) [27]. Крупная фракция - это дискообразные монокристаллические частицы магнетита, средний диаметр которых в плоскости частицы составляет $50-70 \mathrm{~nm}$.

Магнитные наночастицы, полученные электрофизическими методами, сразу после их получения непригодны для непосредственного использования в биомедицинских целях, т. к. они представляют собой ансамбли сильно агрегированных частиц. Последнее связано с наличием как электростатического, так и диполь-дипольного взаимодействия. Одной из важнейших задач, которую приходится решать в данной области, является разработка и получение стабилизированных водных суспензий МНЧ. При этом, возможность получения больших партий наночастиц открывает совершенно новые экспериментальные возможности получения суспензий на основе одной партии МНЧ, но путем использования различных стабилизаторов (как электростатических, стерических, так и стабилизаторов смешанного типа). Таким образом, на основе одной и той же большой партии МНЧ может быть проведена целая серия сравнительных экспериментов с использованием различных суспензий и различных биологических образцов, т. е. обеспечивается возможность наиболее полного и адекватного сравнения результатов.

Одно из направлений исследования возможных биоприложений МНЧ оксида железа - использование феррогелей $(Ф Г)$. Синтез феррогелей в качестве предварительного этапа предполагает получение стабильных суспензий МНЧ. Биологические объекты накладывают жесткие ограничения на условия их тестирования физическими методами, связанные с большим разнообразием сложных процессов в живом организме. Для уменьшения этой неопределенности разрабатывают математические и физические модели, которые воспроизводят только некоторые функции и свойства живой системы.
Например, синтетические гидрогели могут быть использованы в качестве физической модели структурной организации клеток и тканей [13]. Феррогель представляет собой композитный материал на основе полимеpa (рис. 2), набухшего в растворителе, в трехмерную сеть которого интегрированы магнитные наночастицы оксида железа. В качестве базового полимера нами был выбран полиакриламид - широко используемый в медицине биосовместимый материал $[14,15,27]$. Растворителем служила стабилизированная в водной среде суспензия наночастиц маггемита $\left(\gamma-\mathrm{Fe}_{2} \mathrm{O}_{3}\right)$, полученных методом ЛИМ [25,26].

Магнитная аттестация наночастиц и феррогелей осуществлялась с помощью вибрационного и СКВИДмагнитометра: измерялись как петли магнитного гистерезиса, так и термомагнитные кривые $[13,15,23,24]$. На рис. 3 приведены для нескольких температур примеры типичных петель магнитного гистерезиса для наночастиц оксидов железа, полученных электрофизическими методами диспергирования $(a-c)$. Одна из наиболее важных для практических биоприложений тенденций хорошо видна: самой большой намагниченностью насыщения $M_{s}$ обладают ЭВП-наночастицы. ЛИМ-МНЧ занимают промежуточное положение, а ИР-наночастицы имеют наименьшую величину $M_{s}$. В самом общем виде можно сказать, что данная тенденция хорошо согласуется с особенностями фазового состава и размерами обсуждаемых наночастиц (см. описание выше) и имеющимися в современной литературе представлениями о магнитных свойствах наночастиц магнетита и маггемита данных размеров [21-25].

Кроме того, на рис. 3 в качестве примера приведены петли магнитного гистерезиса гидрогеля и серии ФГ с различным содержанием наночастиц маггемита $\gamma-\mathrm{Fe}_{2} \mathrm{O}_{3}$, полученных лазерным испарением мишени. Хорошо видно, что гидрогель характеризуется слабым 
$a$

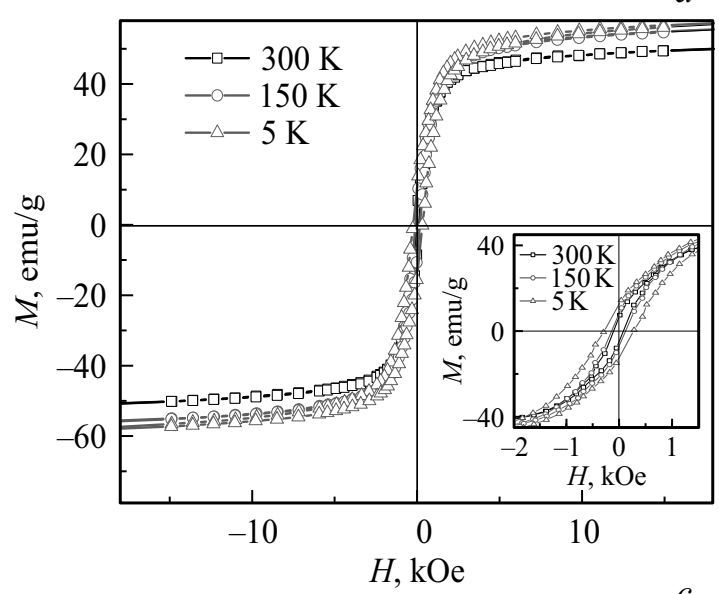

$c$

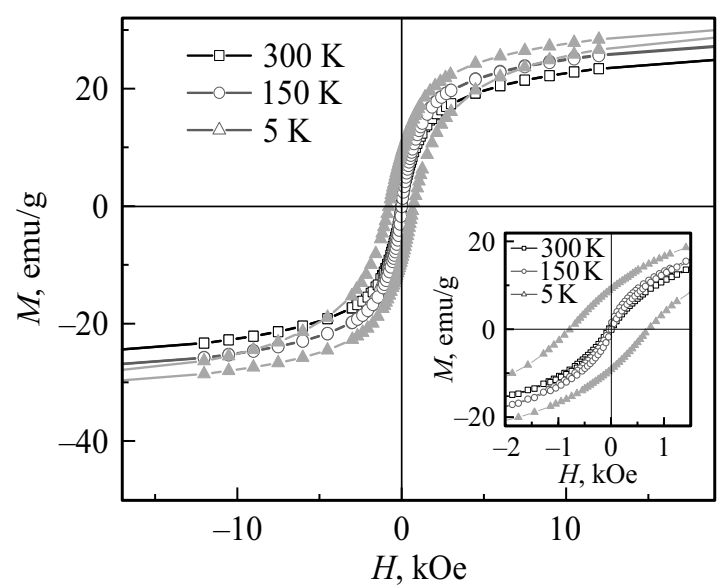

$b$
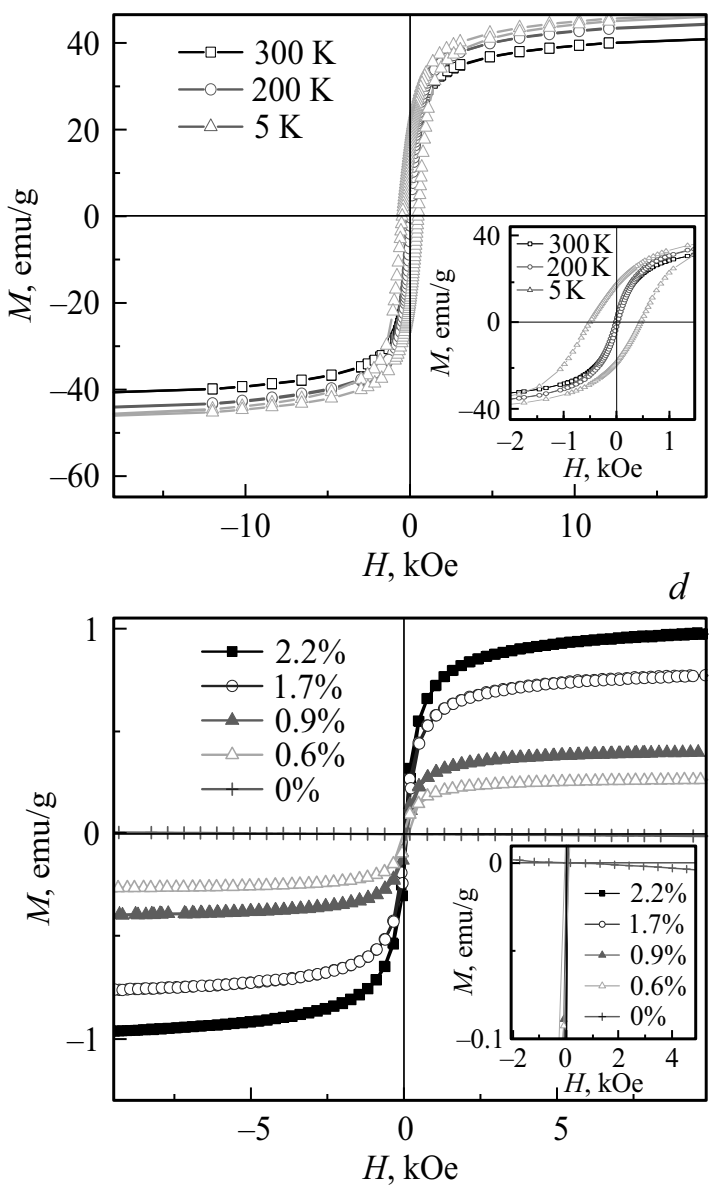

Рис. 3. Петли магнитного гистерезиса, измеренные при нескольких температурах: $a$ ) ЭВП-наночастицы магнетита; $b$ ) ЛИМ-наночастицы маггемита; $c$ ) ИР-наночастицы магнетита - вставки показывают поведение намагниченности в низких магнитных полях; d) петли магнитного гистерезиса гидрогеля и феррогелей на основе акриламида, полученных с использованием ЛИМ-наночастиц маггемита различных концентраций (указаны в весовых процентах); на вставке показано поведение намагниченности в низких магнитных полях: хорошо видно, что отклик гидрогеля — линейный диамагнитный сигнал.

(диамагнитным) откликом при приложении внешнего магнитного поля. Однако добавление небольшого количества наночастиц оксида железа приводит к увеличению магнитного момента до величин порядка emu/g, вполне достаточных для детектирования с помощью чувствительных датчиков слабых магнитных полей.

Петли магнитного гистерезиса пленочных элементов, использованных для экспериментов по магнитному биодетектированию, также измерялись с помощью Керр-микроскопа [31]. Для первичной аттестации многослойных пленочных элементов измерения высокочастотного импеданса были проведены с помощью автоматизированного комплекса магнитоимпедансной спектроскопии, основу которого составлял анализатор импеданса Agilent E4991A. Подробное описание данной методики представлено в работе [27]. Относительное изменение ГМИ во внешнем магнитом поле $H$, приложенном вдоль длинной стороны прямоугольного ГМИ-элемента, определялось следующим образом: $\Delta Z / Z=100 \% \cdot\left(Z(H)-Z\left(H_{\max }\right)\right) / Z\left(H_{\max }\right)$, где
$H_{\max }=100 \mathrm{Oе}-$ максимальное внешнее магнитное поле, создаваемое катушками Гельмгольца. Далее аттестованные элементы использовались для разработки автономного пленочного детектора ГМИ, особенности работы которого будут описаны ниже. Кроме того, для проведения модельных экспериментов с использованием автономного детектора слабых магнитных полей и его калибровки была получена серия образцов композитов на основе коммерческих наночастиц магнетита.

При выборе МНЧ оксидов железа для каждого конкретного приложения оцениваются как размер МНЧ, так и их химический состав и магнитные свойства. Несмотря на то, что выше мы указали средние размеры, характерные для каждого из рассматриваемых электрофизических методов, существует возможность варьировать как средний размер, так и особенности распределения по размерам наночастиц партии с помощью намеренного изменения технологических параметров в процессе получения МНЧ оксидов железа $[23-25,27]$. 
$a$

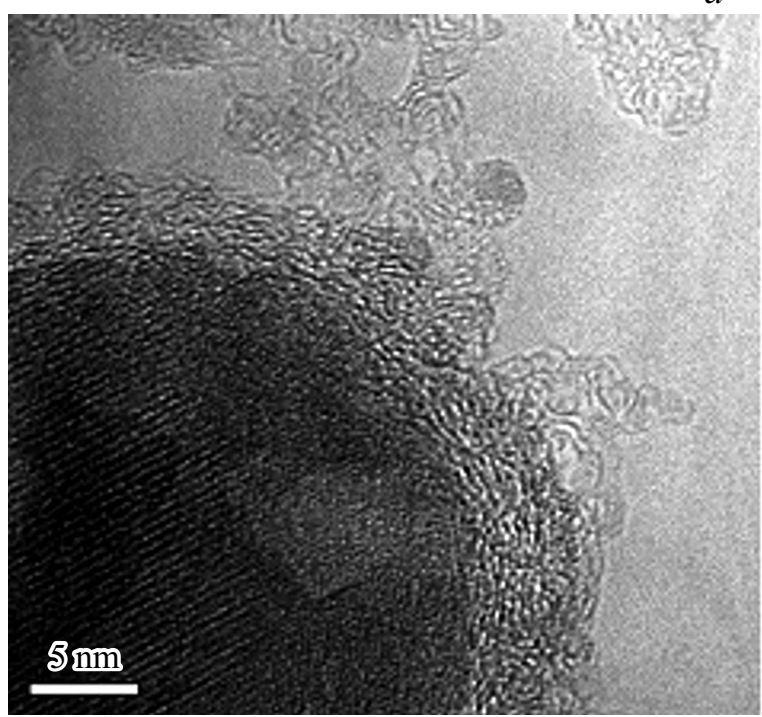

$b$

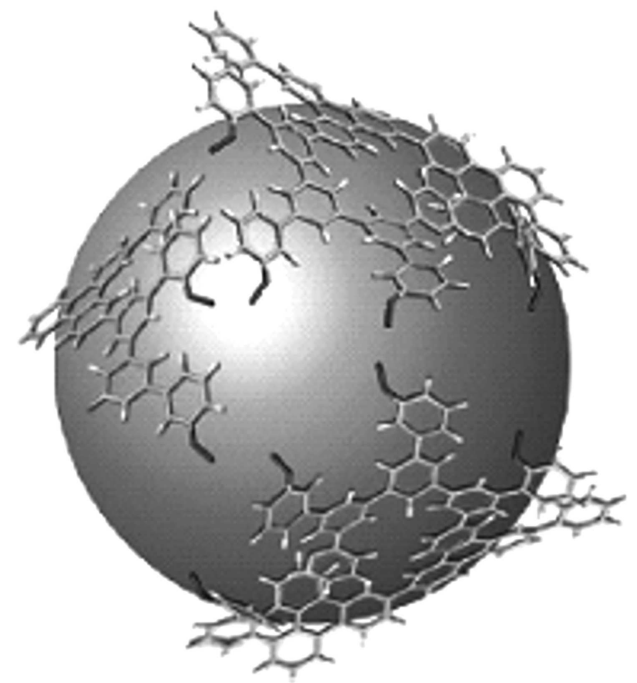

Рис. 4. Дефектное графеноподобное углеродное покрытие на поверхности ЭВП-наночастицы железа после выдержки в метилбензоле: $a$ ) высокоразрешающая электронная микроскопия (поле зрения $-35 \times 35 \mathrm{~nm}$ ); $b$ ) схема наночастицы с углеродным покрытием.

\section{3. Примеры перспективных приложений магнитных наночастиц, полученных электрофизическими методами}

\section{1. Наночастицы, получаемые методом электрического взрыва проволоки: низкотемпературная конденсация углерода}

В случае наночастиц, синтезированных методом электрического взрыва проволоки, следует упомянуть интересный результат, полученный для ЭВП-наночастиц чистого железа, а именно, возможность создания на их поверхности дефектного графеноподобного углеродного покрытия при взаимодействии интактных поверхностей МНЧ (рис. 3) с ароматическими сольвентами при нормальном давлении и комнатной температуре [33]. Более того, было показано, что подобное покрытие может формироваться на поверхности тонких пленок железа и пермаллоя, и предложенный процесс его получения (выдержка в ароматических сольвентах в течение оптимального срока) может улучшать функциональные свойства многослойных пленочных элементов, работающих на основе явления ГМИ [34]. Последний эффект, по-видимому, связан с особенностями релаксации внутренних напряжений, приводящей к снижению дисперсии осей локальной магнитной анизотропии в приповерхностных областях многослойного пленочного элемента. Кроме того, существование углеродного покрытия на поверхности чувствительного ГМИ-элемента может приводить к улучшению условий функционализа- ции его поверхности в биологических экспериментах по магнитному детектированию (рис. 4).

Механизм осаждения углерода на границе раздела, вероятно, представляет собой гетерогенное окисление ароматических углеводородов по типу Шолла, путем катионной полимеризации арильных колец. Образуются полициклические ароматические углеводороды, химически связанные с поверхностью МНЧ. В отличие от плотных графитовых слоев, возникающих при других способах получения углеродного покрытия, полициклические слои, хотя и связаны с ней химически, не прикреплены к поверхности плотно. Такая „волосовидная“ структура углеродистого отложения может быть особенно благоприятной для применений, предполагающих усиление взаимодействие на поверхностях, включенных в функциональные матрицы (полимерные композиты или биосенсоры). Ароматическая химическая природа углеродного покрытия данного типа обеспечивает сильное взаимодействие с большинством полимеров, а его рыхлая структура способствует конформационной подвижности макромолекулярных цепей на границе раздела.

В работах других исследователей [35,36] ЭВП-МНЧ были изучены как основа композиционного материала для магнитолюминесцентной диагностики в ближней инфракрасной области спектра 700-1100 nm и тераностики раковых опухолей. Ядро композита представляет собой ЭФП-МНЧ магнетита, которое может обеспечивать проведение процедуры локальной гипертермии, а иттербиевые комплексы порфиринов могут быть использованы в качестве одного из основных компонентов для люминесцентной диагностики. Например, было показано, что наличие магнетитового ядра лишь незначительно 
снижает люминесценцию Yb-комплекса в синтезированных нанокомпозитах, добавляя возможность адресной доставки и проведения гипертермии [36].

Ранее авторы данной работы исследовали как ЭВП-МНЧ чистого железа [33,37], так и МНЧ магнетита [24,25]. Наночастицы железа из-за своей пирофорности требуют пассивации поверхности, т.е. создания тонкого поверхностного слоя оксида железа за счет введения во взрывную камеру определенного количества кислорода. Толщина оксидной оболочки в данном случае составляет несколько нанометров. Поскольку в технологическом процессе ЭВП для получения как МНЧ чистого железа, так и МНЧ оксидов железа используется железная проволока, то для получения наночастиц оксида железа во взрывную камеру подается, помимо основного рабочего газа (азота, доля которого составляет около $80 \%$ ), точно рассчитанное количество кислорода. Таким образом, путем аккуратного подбора параметров синтеза существует возможность получения ЭВП-МНЧ нового типа - c достаточно большой толщиной оболочки оксидов железа и небольшим ядром чистого железа. Ранее мы доказали возможность существования таких наночастиц - как методами рентгенофазового анализа, так и с применением микроволновых методик $[23,24]$. Хотя до настоящего времени ЭВП-МНЧ еще не были исследованы экспериментально в вышеописанном контексте, можно предположить, что их введение и удерживание в зоне опухоли, осуществляемое с использованием градиентного магнитного поля, может существенно снизить локальную концентрацию кислорода и оказывать желаемое терапевтическое воздействие.

\section{2. Наночастицы оксидов железа, получаемые методами ЭВП и лИМ: возможность получения водных суспензий}

В наших первых работах, посвященных ЭВП-МНЧ магнетита [23,24], особое внимание было уделено созданию деагрегированных сферических наночастиц с узким распределением по размерам. Чтобы обеспечить стабильность суспензии магнетита в воде, была найдена оптимальная концентрация электростатического стабилизатора (цитрата натрия) и оптимальный уровень $\mathrm{pH}$ на основе измерений дзета-потенциала. После электростатической стабилизации суспензии все еще содержали значительную долю агрегатов, которые удавалось разрушать адекватной обработкой ультразвуком. Центрифугирование позволило отделить крупные частицы от суспензии. Анализ особенностей структуры, магнитных свойств и микроволнового поглощения МНЧ подтверждал, что полученный ансамбль представляет собой совокупность деагрегированных сферических суперпарамагнитных МНЧ. Максимальная полученная концентрация составила $5 \mathrm{wt} \%$ ЭВП-МНЧ.

Несмотря на большую производительность метода ЭВП, наиболее часто в исследованиях использовали
ЛИМ-МНЧ, которые тоже могут быть получены партиями в количестве порядка десятков граммов. Биологическим экспериментам также предшествовала всесторонняя аттестация особенностей структуры, магнитных свойств и микроволнового поглощения [25]. Отметим здесь только два наиболее интересных факта. Первый из них: установлена возможность получения стабильной водной суспензии ЛИМ-МНЧ без использования дополнительных стабилизаторов. Максимальная полученная концентрация такой самостабилизированной и стабильной в условиях окружающей среды суспензии составляла $10 \mathrm{~g} / 1 \mathrm{MHЧ.} \mathrm{Особенности} \mathrm{самостабилизации}$ ЛИМ-МНЧ оксида железа в воде похожи на особенности процесса стабилизации ЭВП-наночастиц оксида алюминия [38]. Они связаны с условиями конденсация наночастиц в окислительной атмосфере (смесь $\mathrm{N}_{2}+\mathrm{O}_{2}$ ) при лазерном испарении. Хотя азот не реагирует с кислородом при температуре окружающей среды, реакция может происходить при повышенных температурах в перегретом облаке распыленных паров оксида металла с образованием молекул оксидов азота. Наночастицы конденсированных оксидов металлов могут адсорбировать оксиды азота, обеспечивая образование нитратов на их поверхности. Хотя точный химический состав нитратов металлов, адсорбированных на границе раздела, с уверенностью нельзя предсказать, кажется разумным, что они могут участвовать в гидролитической диссоциации в воде, как и любая растворимая соль тяжелого металла.

Второй интересный факт связан с особенностями магнитных свойств ЛИМ-МНЧ. Наблюдаемое магнитное поведение было описано в терминах структуры ядро-оболочка отдельной наночастицы с учетом эффекта взаимодействия намагниченности ядра и оболочки частицы в рамках модели случайной анизотропии. Наночастицы имеют ферримагнитное ядро, занимающее примерно 70\%, тогда как оболочка состоит из поверхностных слоев, в которых спины заморожены и отсутствует дальний магнитный порядок [25].

\section{3. Водные суспензии ЛИМ-наночастиц маггемита, получаемые на основе одной и той же партии: примеры биологических экспериментов}

В одной из наиболее интересных серий экспериментов с ЛИМ-МНЧ одной и той же партии были использованы для получения стабилизированных суспензий на водной основе с применением электростатической или стерической стабилизации природным полимером хитозаном [25]. Инкапсуляция МНЧ хитозаном делает их устойчивыми к неблагоприятным факторам коллоидной стабильности, которые обычно присутствуют в физиологических условиях, таких как $\mathrm{pH}$ и высокая ионная сила. Контролируемые количества суспензий использовали в экспериментах in vitro с мононуклеарными лейкоцитами крови человека и с мезенхимальными стволовыми 
$a$
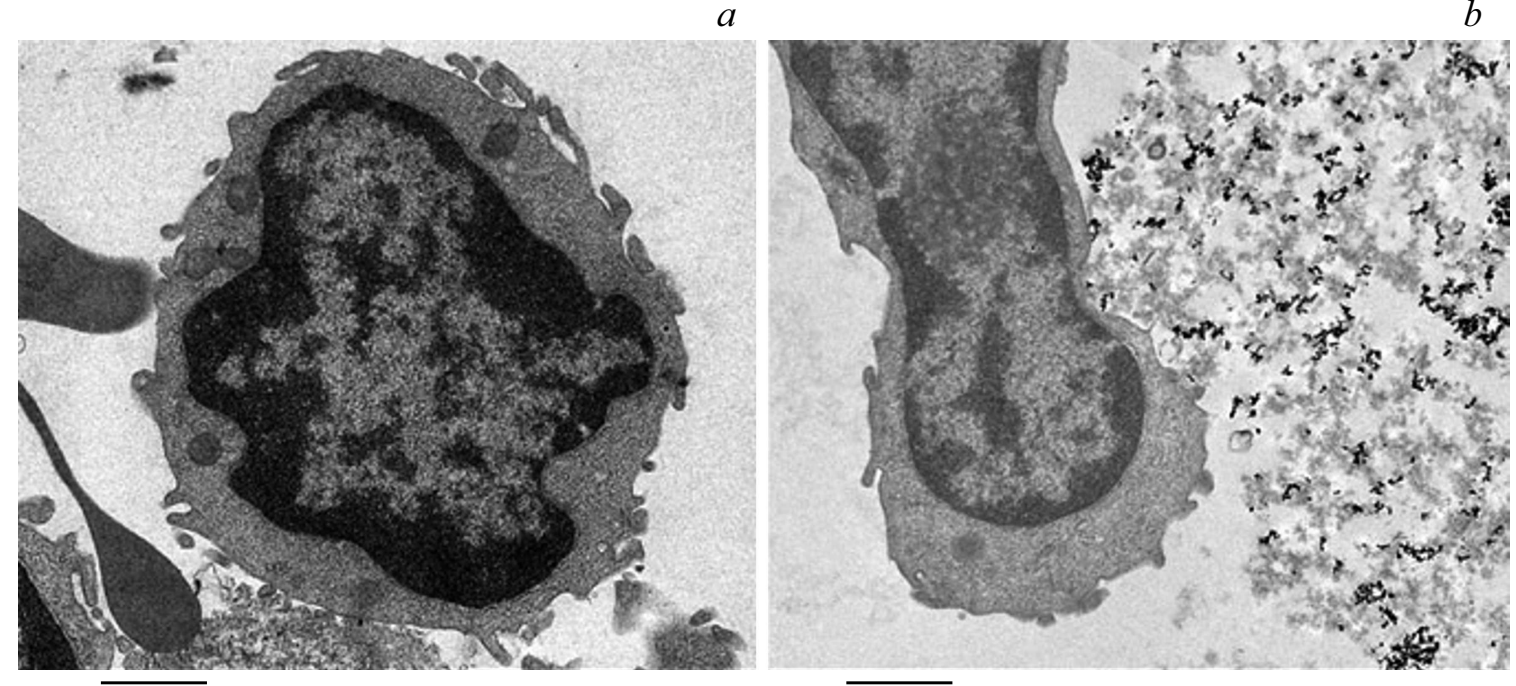

$1 \mu \mathrm{m}$

$c$

$1 \mu \mathrm{m}$

$d$
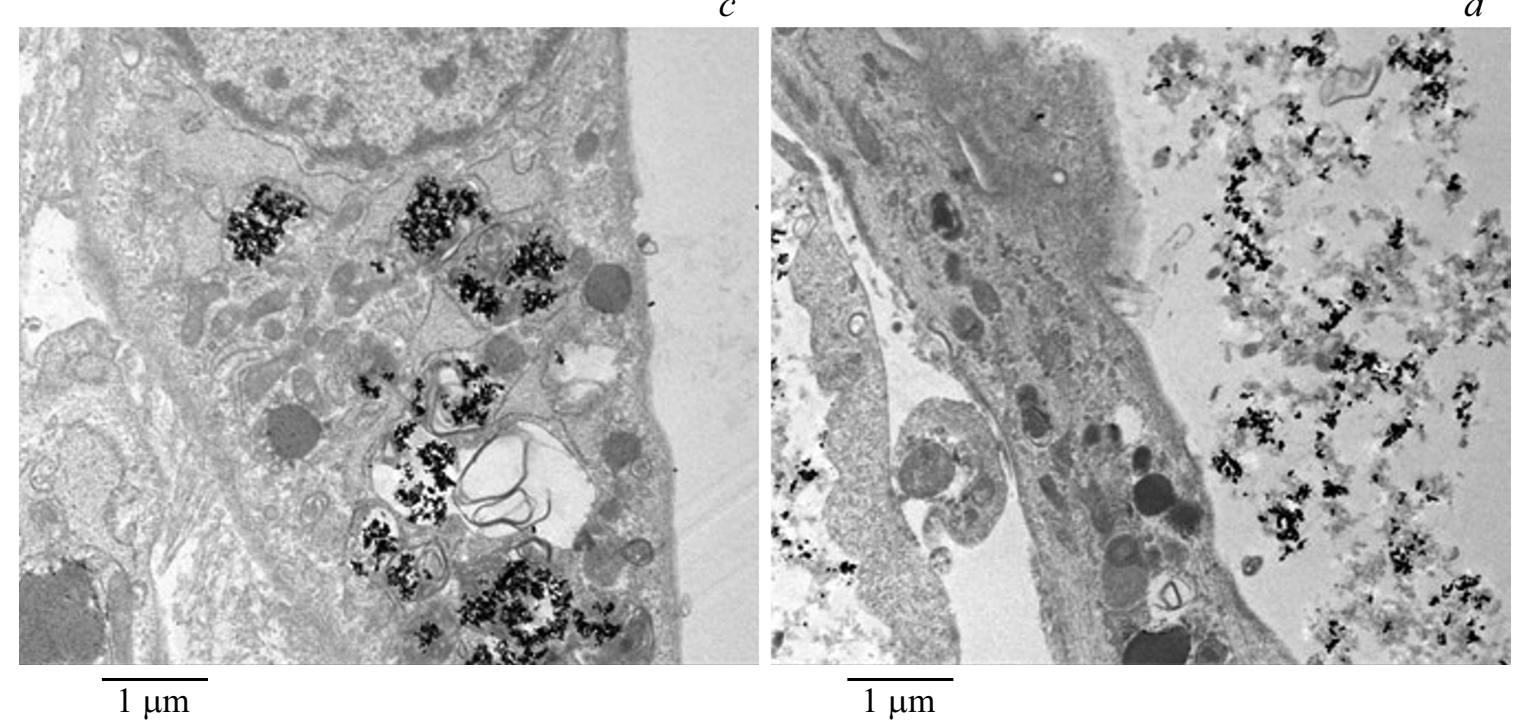

Рис. 5. Просвечивающая электронная микроскопия. Мононуклеарные лейкоциты крови человека после 24-часового контакта с ЛИМ-МНЧ суспензий оксида железа: $a$ ) без хитозана, $b$ ) с хитозаном. Мезенхимальные стволовые клетки человека после 24-часового контакта с ЛИМ-МНЧ суспензии оксида железа: $c$ ) без хитозана, $d$ ) с хитозаном. Во всех случаях использовали дозу 100 ПДК, предельно допустимых концентраций $(1$ ПДК $=0.3 \mathrm{~g} / \mathrm{l})$ и время выдержки 24 hours в контакте с МНЧ. Поле зрения во всех случаях $-5.8 \times 6.9 \mu \mathrm{m})$.

клетками человека с целью изучения их морфофункционального ответа (рис. 5). Например, суспензии с хитозаном и без него усиливали секрецию цитокинов в 24-часовой культуре мононуклеарных лейкоцитов крови по сравнению с контролем без МНЧ. Обе суспензии не вызывали гибели клеток из-за некроза, следовательно, секреция цитокинов происходила за счет повышения функциональной активности мононуклеарных лейкоцитов. В случае мезенхимальных стволовых клеток человека и суспензии без хитозана наблюдались внутриклеточные включения МНЧ, в основном агрегированные внутри органелл.

В цитоплазме клетки свободно располагались только единичные включения. Агрегаты МНЧ были отмечены внутри эндосом, а также по контуру секреторных гранул и внешней мембраны митохондрий. Как правило, в митохондриях накапливались крупные агрегаты. МНЧ в случае суспензии с хитозаном в меньшей степени проникали в клетки по сравнению с МНЧ суспензии без хитозана. Включения, если таковые наблюдались, располагались по контуру секреторных гранул. Сделан вывод о том, что полученные результаты могут быть использованы для адресной доставки лекарств или удаления клеток, а также в области разработки биосенсоров для обнаружения магнитных меток $[39,40]$.

В целом ряде работ мы рассматривали вопросы биосовместимости и особенностей ответных реакций на воздействие разных концентраций ЛИМ-МНЧ оксида 

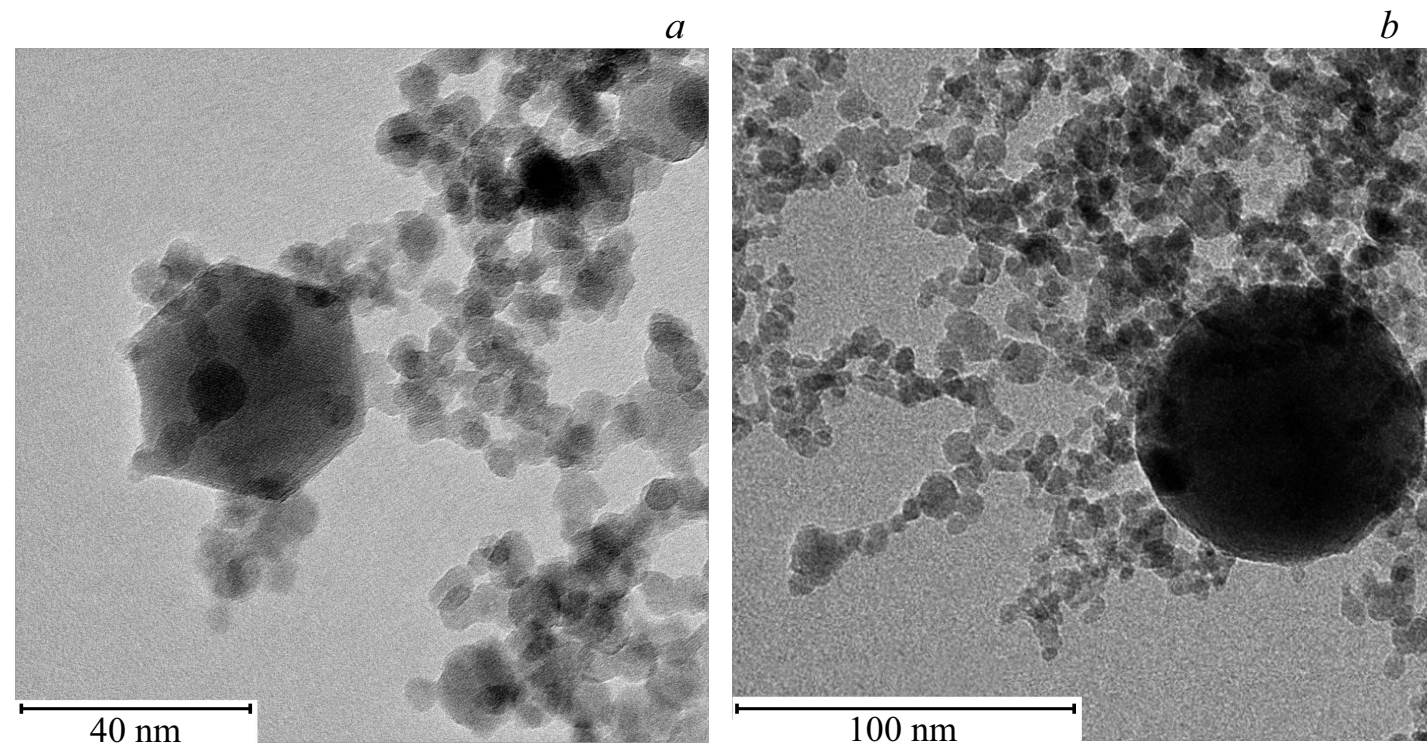

Рис. 6. Просвечивающая электронная микроскопия ИР МНЧ магнетита: $a$ ) мелкая фракция МНЧ (поле зрения $-35 \times 35 \mathrm{~nm}$ ); b) помимо мелкой фракции, в поле зрения попала одна плоская наночастица, размер диаметра которой составляет около $60 \mathrm{~nm}:$ по особенностям изображения, частица достаточно прозрачна, можно утверждать, что ее толщина не превышает $20 \mathrm{~nm}$ (поле зрения $-35 \times 35 \mathrm{~nm})$.

железа на примере различных биологических объектов (Chlorella vulgaris Beijer IRK-A 46, Exophiala nigrum R-11 и др.). Например, культура хлореллы демонстрирует ответную реакцию на воздействие разных концентраций ЛИМ-МНЧ оксида железа. Концентрации 0.5-1.0 ПДК вызывают стимулирующий эффект на рост культуры тест-объекта ( 1 ПДК $=0.3 \mathrm{~g} / 1)$. Концентрация 1000 ПДК характеризуется как токсичная, а 100 ПДК как умеренно токсичная. В случае Exophiala nigrum R-11 показано стимулирующее действие суспензии с ЛИМ-МНЧ в концентрациях 100 и 1000 ПДК. Полученные результаты могут быть интересны как с точки зрения оценки экологического импакта МНЧ, так и при подборе модельных образцов для систем магнитного биодетектирования $[8,39]$.

Водные суспензии ЛИМ-МНЧ были исследованы с точки зрения их эффективности как материалов для гипертермии и термоабляции $[8,40,41]$. Удельная мощность потерь была измерена для водных суспензий ЛИМ-МНП $\gamma-\mathrm{Fe}_{2} \mathrm{O}_{3}$ с помощью нескольких методов. Статические петли магнитного гистерезиса недооценивают потери мощности, поскольку динамические эффекты не вносят вклада при их измерении, но они оказались ценным инструментом для доказательства согласованности измерений удельной мощности потерь, полученных другими методами в широком диапазоне магнитых полей. Простые теоретические модели среднего поля (взаимодействующих суперпарамагнитых частиц, модифицированная модель Стонера-Вольфарта) были использованы для воспроизведения статических потерь энергии ЛИМ-МНЧ [41].

\section{4. Наночастицы ЛИМ-магнетита - возможные материалы для магнитомеханической терапии?}

Последним из рассматриваемых и наименее продуктивным электрофизическим методом является метод искрового разряда, позволяющий получать партии МНЧ в несколько граммов. Одним из интересных аспектов, который может привлечь к этому методу особое внимание является возможность получения с его помощью МНЧ очень необычной геометрии, фактически монокристаллических нанодисков оксида железа. Частицы такой формы могут представлять интерес для магнитомеханической терапии $[19,42]$. До настоящего времени для ее проведения использовали магнитные нанопроволоки или нанодиски, получаемые на основе тонких пленок путем литографии $[19,42]$. Типичный размер таких дисков составляет около $500 \mathrm{~nm}$ в диаметре при толщине около $30 \mathrm{~nm}$. Ранее мы сообщали о возможности получения сферических МНЧ, средний диаметр которых составляет 5-8 nm. Однако было показано, что наряду с мелкими ИР-МНЧ магнетита (рис. 6) в состав ансамбля входило небольшое количество (порядка 10\%) плоских монокристаллических МНЧ, которые по данным рентгенофазового анализа и электронной микроскопии также представляли собой магнетит [43].

Мелкие ИР-МНЧ имели очень большие внутренние деформации порядка $25 \cdot 10^{-3}$ [42], редко достигаемые даже в случае материалов, получаемых методом многочасового синтеза в шаровых мельницах [44]. Такие высокие уровни деформаций могут играть важную роль в процессе функционализации поверхности и взаимо- 
действия с разными биосистемами. Крупные плоские наночастицы, в случае, если их удастся отделить от мелкой фракции, можно было бы использовать в качестве нанодисков для магнитомеханической терапии. При размере партии в несколько граммов ИР-наночастиц можно ожидать получение партии нанодисков около $0.5 \mathrm{~g}$, что заметно выше размера партий нанодисков, получаемых в настоящее время методами литографии.

\section{5. Применение магнитных композитов в биофизических и биомедициских приложениях}

Большая часть исследований, описываемых в данном разделе, была проведена с использованием феррогелей на основе ЛИМ-МНЧ. Например, полученные нами феррогели были использованы в качестве биомиметиков для разработки ГМИ-биосенсора, способного определять концентрацию МНЧ в живых тканях. В экспериментах по магнитному биодетектированию концентрация МНЧ в ФГ варьировалась от 0 до $2.2 \mathrm{wt} \%$. Пример магнитной аттестации магнитных свойств таких материалов обсуждался выше (см. рис. 3). ГМИ-элемент представлял собой многослойную пленочную структуру $[\mathrm{Cu} \mid \mathrm{FeNi}]_{5}|\mathrm{Cu}|[\mathrm{FeNi} \mid \mathrm{Cu}]_{5}$. Зависимость отклика ГМИ от концентрации МНЧ при фиксированном значении напряженности внешнего поля была линейна. При частоте $80 \mathrm{MHz}$ и напряженности внешнего магнитного поля $7.6 \mathrm{Oе}$ чувствительность прототипа датчика к изменению концентрации МНЧ составляла около $1.3 \mathrm{wt} \%$ или $4.3 \% / \mathrm{mg}$. Для описания экспериментальных результатов была предложена электродинамическая модель ГМИ в многослойной пленке со слоем ФГ [15]. Здесь следует добавить, что чувствительности ГМИ-биосенсора было достаточно и для детектирования объемной скорости течения суспензий МНЧ в модельных сосудах с переменным сечением [44]. Подобного рода эксперименты были выполнены с целью обоснования возможности водных суспензий на основе ЛИМ МНЧ для контрастирования артерий в диагностических целях.

Проблема использования магнитных композитов в качестве магнитоуправляемых платформ для инженерии тканей исследовалась в многочисленной серии экспериментов с культурами клеток in vitro $[14,29,45,46]$. Тестировалась биосовместимость ФГ с различными механическими и электрическими свойствами в диапазоне концентраций МНЧ от 0 до $2 \mathrm{wt} \%$. Испытания проводились на лейкоцитах периферической крови человека, дермальных фибробластах человека, стволовых мезенхимальных клетках человека и хондроцитах хрящевой ткани крыс. Биосовместимость характеризовалась по плотности монослоя клеток на поверхности ФГ через 12 и 96 часов их инкубации в стандартных условиях. Важно подчеркнуть, что все проведенные нами эксперименты были выполнены с использованием ЛИМ-МНЧ из одной партии, хотя и в различное время.
Установлено, что биологическая активность клеток на ФГ критическим образом возрастала с увеличением концентрации МНЧ в композите, но в меньшей степени зависела от электрических и механических свойств материала. Данное заключение было справедливо для всех типов клеток. Например, через 96 часов культивирования фибробластов человека плотность монослоя клеток на ФГ с концентрацией МНЧ 2 wt\% была почти в два раза больше, чем на ФГ с $1 \mathrm{wt} \%$ МНЧ, при том, что эти композиты имели близкие по величине модуль Юнга $(\sim 45 \mathrm{kPa})$ и электрический потенциал $(\sim-40 \mathrm{mV})$ [44]. С теоретической точки зрения полученные факты означают, что непосредственно МНЧ могут оказывать позитивное действие на биологическую активность клеток.

Принципиально важными является наши находки, полученные в результате тестирования биологической активности клеток (фибробластов, хондроцитов и мезенхимальных стволовых клеток) на поверхности ФГ в присутствии умеренного постоянного магнитного поля ( 450 Ое). Для этого, из-за отсутствия коммерческих аналогов, был спроектирован и изготовлен оригинальный источник магнитного поля на основе 24 цилиндрических постоянных магнитов, помещенных в лунки стандартного планшета для культивирования клеток. Показано, что в условиях приложения внешнего постоянного магнитного поля сохраняются все закономерности, характеризующие связь между адгезивной и пролиферативной активностями клеток и концентрацией МНЧ в композите [29].

В экспериментах на животных in vivo (10 кроликов породы „Советская шиншилла“) исследовалось взаимодействие ФГ с биологически агрессивными средами живого организма, путем оценки стойкости имплантов к разрушающему воздействию, реакции периимплантационных тканей и периферических органов иммунной системы на внедрение ФГ, а также особенностей регенераторного процесса хрящевой и костной тканей при замещении костно-хрящевого дефекта имплантатами (рис. 7).

Для этого кроликам в области передней поверхности дистального эпиметафиза бедренной кости, на конечностях были сформированы цилиндрические костнохрящевые дефекты. Контролем являлись незамещенные дефекты, в опытной серии 1 дефекты были замещены цилиндрическими имплантатами из ФГ на основе полиакриламида с плотностью сшивки 1:100 и концентрацией МНЧ $1.3 \%$ (рис. 7,a), в серии 2-1 дефекты были замещены имплантатами из ФГ с адгезированными на их поверхности аллогенными хондроцитами. Срок наблюдения составлял 30 суток после операции. Использовали как морфологические, так и морфометрические методы исследования. В области дефекта оценивали площадь и зрелость новообразованных тканей, количество хондроцитов; в периимплантационных тканях определяли количество новообразованных сосудов, провоспалительных клеток, макрофагов, содержащих трехвалентное железо в гранулах. Для оценки реакции иммунной системы 


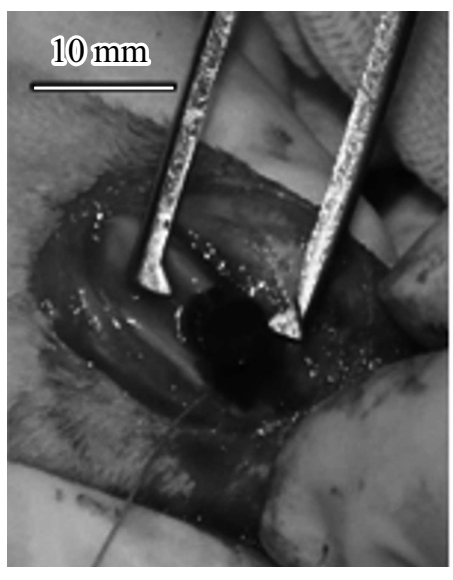

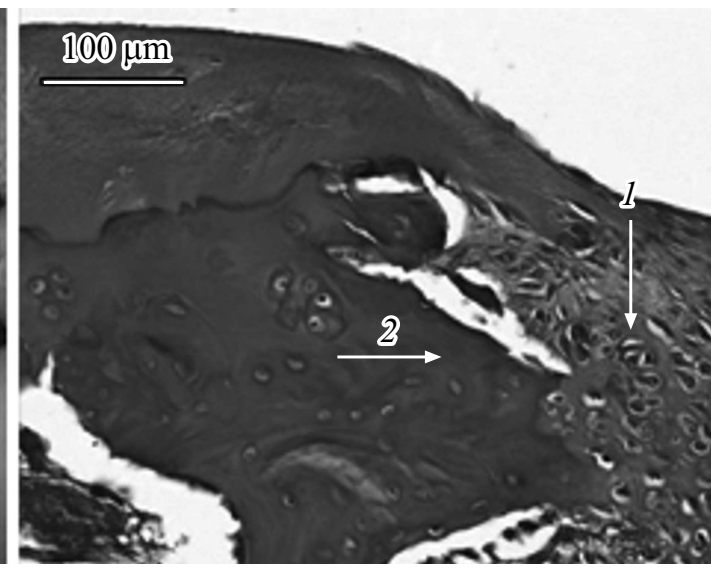

$b$

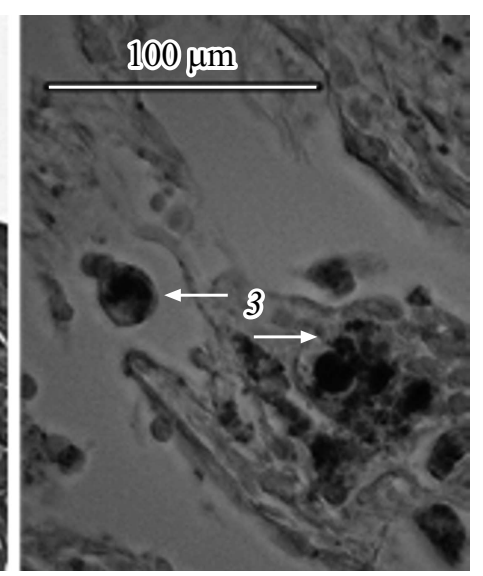

Рис. 7. Результаты экспериментов с животными. $a$ ) внедрение имплантируемого образца ФГ в специально созданный дефект бедренной кости кролика; $b$ ) и $c$ ) - микропрепараты, полученные через 30 суток после операции, дефект заполнен ФГ-имплантатом (серия 1): $b$ ) краевая зона регенерата над полостью дефекта (граница „дефект-периимплантационная область“), 1 - область новообразованной хрящевой ткани; 2 - новообразованные костные балочки (окраска гематоксилином и эозином); c) периимплантационные ткани. 3 - скопление макрофагов с гранулами, окрашенными на трехвалентное железо (окраска по Перлсу).

были изучены регионарные лимфатические узлы 1-го порядка, в которых оценивали структурно-функциональные зоны, их площади, количество вторичных лимфоидных фолликулов.

Установлено, что ФГ не интегрировались с костной и хрящевой тканями. В области специально созданного дефекта бедренной кости наблюдались новообразованные хрящевая, костная (рис. 7,b) и соединительная ткани. Композиты проявили себя как легкий раздражитель по сравнению с отрицательным контролем: выраженных признаков отторжения имплантатов выявлено не было, но имели место признаки их деградации. В частности, в периимплантационных тканях были выявлены макрофаги, содержащие в гранулах трехвалентное железо (рис. 7,c). При исследовании регионарных лимфатических узлов клеточная атипия отсутствовала, были выявлены признаки асептического воспаления. При внедрении ФГ с аллогенными хондроцитами по сравнению с ФГ без клеток было установлено более выраженные раздражение периимплантационных тканей и иммунная воспалительная реакция в регионарных лимфатических узлах, что обусловлено введением аллогенных клеток. Однако было отмечено ускорение регенерации костной ткани, что проявлялось в увеличении площади костной ткани и ее зрелости в зоне сформированного дефекта. Полученные данные позволяют полагать, что в определенных условиях ФГ могут быть использованы в качестве материала для клеточных платформ-имплантатов. Предварительные результаты данного исследования были изложены в работе [20].

Необходимо упомянуть, что возможность детектирования ФГ-имплантатов или же средств адресной доставки лекарств на их основе в биологических средах была продемонстрирована нами в экспериментах с ультразвуковой локацией образцов композитов различной формы [46]. Кроме того, первые обнадеживающие результаты получены при детектировании магнитных композитов на основе эпоксидной смолы с помощью разработанного нами автономного детектора слабых магнитных полей на основе ГМИ-датчика с пленочным элементом (см. ниже).

\section{6. Автономный пленочный ГМИ сенсор для детектирования полей рассеяния магнитных частиц}

Создание чувствительного элемента для определения концентрации МНЧ, внедренных в живые ткани - важная задача биоприложений. Эффект гигантского магнитного импеданса (ГМИ), обеспечивающий высочайшую чувствительность по отношению к внешнему магнитному полю, является перспективным кандидатом для создания ГМИ-биосенсора $[13,15,20,47-48]$. Явление ГМИ заключается в значительном изменении полного комплексного сопротивления ферромагнитного проводника при приложении внешнего магнитного поля $[15,30]$. Принцип работы такого компактного аналитического устройства основан на измерении суммарных полей рассеяния МНЧ. Пленочные наноструктуры для ГМИ чувствительных элементов были получены методом ионно-плазменного распыления на стеклянные подложки. Элементы осаждались с использованием металлических масок в условиях приложения внешнего технологического поля $H=250$ Ое. Готовые элементы представляли собой полоски $0.5 \times 10.0 \mathrm{~mm}$, с наведенной вдоль короткой стороны одноосной магнитной анизотропией. Особенности структуры элементов 


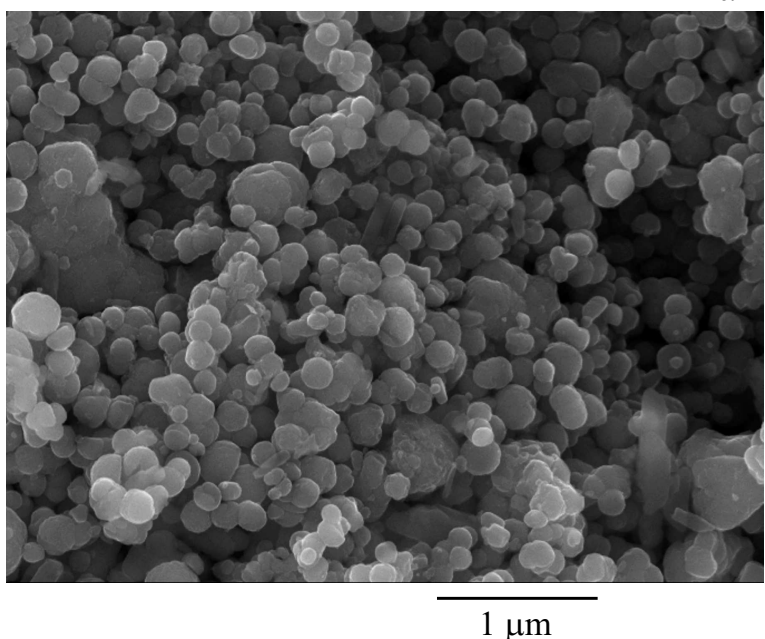

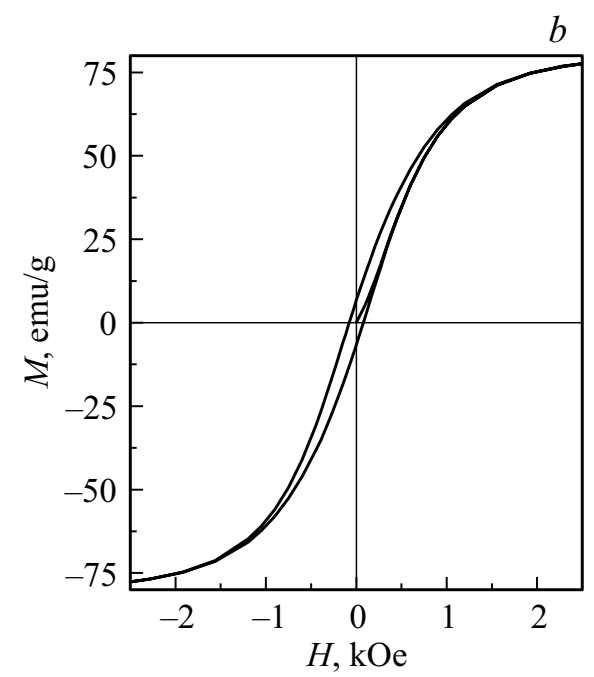

Рис. 8. Характеристики наночастиц, использованных для эпоксикомпозитов: $a$ ) сканирующая электронная микроскопия (поле зрения $-3.7 \times 4.9 \mu \mathrm{m}) ; b$ ) петля магнитного гистерезиса, измеренная при комнатной температуре.

были выбраны таким образом, чтобы избежать перехода в закритическое состояние $[15,49,50]$ в каждом отдельном магнитном слое и обеспечить высокий эффект ГМИ: $[\mathrm{Ti}(6 \mathrm{~nm}) \mid \mathrm{FeNi}(50 \mathrm{~nm})]_{5}|\mathrm{Ti}(6 \mathrm{~nm})| \mathrm{Cu}(500 \mathrm{~nm})|\operatorname{Ti}(6 \mathrm{~nm})|$ $[\mathrm{FeNi}(50 \mathrm{~nm}) \mid \mathrm{Ti}(6 \mathrm{~nm})]_{5}$. Более подробно критерии выбора толщин слоев и процедура получения ГМИ элементов описаны в работах $[13,15]$.

Ранее мы упоминали работы, в которых была доказана возможность детектирования полей рассеяния магнитных ЛИМ-наночастиц ФГ в конфигурации, когда образец ФГ находился в прямом контакте с пленочным ГМИ-элементом. Для практики также очень важен режим детектирования полей рассеяния магнитных наночастиц в конфигурации, когда чувствительный элемент и объект детектирования находятся на определенном расстоянии друг от друга. Поскольку интенсивность поля рассеяния частицы обратно пропорциональна кубу расстояния между частицей и точкой измерения, последняя из упомянутых конфигураций предьявляет очень высокие требования к чувствительности сенсора, используемого для детектирования слабых магнитных полей. Потому для разработки прототипа на первом этапе нами были использованы цилиндрические образцы эпоксикомпозитов с различным содержанием коммерческих наночастиц (рис. 8) $\mathrm{FeO}_{x}\left(\right.$ фазы $\mathrm{Fe}_{3} \mathrm{O}_{4}-94 \mathrm{wt} \%$; $\mathrm{Fe}_{2} \mathrm{O}_{3}-1 \mathrm{wt} \%$ и $\left.\mathrm{FeO}(\mathrm{OH})-5 \mathrm{wt} \%\right)$. Средний размер микрочастиц составлял примерно $200 \mathrm{~nm}$.

Многослойные пленочные элементы типа $\quad[\mathrm{Ti} \mid \mathrm{FeNi}]_{5}|\mathrm{Ti}| \mathrm{Cu}|\mathrm{Ti}|[\mathrm{FeNi} \mid \mathrm{Ti}]_{5}$ обладали одноосной магнитной анизотропией с малой дисперсией локальных осей легкого намагничивания (рис. 9, $a$ и $b$ ). Анализ измеренных частотных и полевых зависимостей магнитоимпедансного отношения позволил отобрать элемент с чувствительностью до $50 \% / \mathrm{Oe}$ (до $4 \Omega / \mathrm{Oe}$ ) для создания детектора слабых магнитных полей. Наибольшая крутизна характеристики наблюдалась на частоте, близкой к $73 \mathrm{MHz}$. На основе разработанного квадратурного демодулятора сигналов ГМИ-датчика создан детектор слабых магнитных полей с пленочным ГМИ-элементом (рис. 9,c). Держатель вставлен в катушку подмагничивания. На катушку подается стабилизированный постоянный ток величиной от 0.1 до $10 \mathrm{мA}$ для обеспечения смещения постоянного магнитного поля в зону максимальной чувствительности пленочного элемента. Для смещения рабочей точки ферромагнитного пленочного элемента в область максимальной чувствительности датчик снабжен катушкой (coil, puc. 9,c), по которой протекает постоянный ток, вырабатываемый прецизионным источником тока Хауленда (current source, рис. 9,c). Напряженность постоянного магнитного поля, создаваемого данной катушкой для обеспечения максимальной крутизны характеристики ГМИ-элемента, составляет 3.8 Ое при протекании по катушке постоянного тока $3.8 \mathrm{~mA}$.

Основные особенности работы детектора слабых магнитных полей можно описать следующим образом. Чувствительный элемент включен в параллельный колебательный контур резонансного усилителя, обеспечивающего минимальный уровень собственных шумов. Синусоидальный сигнал частотой $75 \mathrm{MHz}$ и амплитудой $240 \mathrm{mVpp}$ (peak-to-peak) подается от прецизионного генератора Rigol DG-4202 на вход резонансного усилителя, обеспечивая функционирование датчика при уровне мощности переменного электромагнитного поля менее $-15 \mathrm{dBm}$. Сигнал от датчика поступает через полосовой фильтр FTR-3874 с центральной частотой $75 \mathrm{MHz}$ и шириной полосы пропускания $32 \mathrm{kHz}$ по уровню $-3 \mathrm{~dB}$ на вход квадратурного демодулятора сигнала, выполненного на аналоговых перемножителях. Амплитуда напряжения сигнала на выходе фильтра составляет $-26 \mathrm{dBm}$ при уровне шума $-90 \mathrm{dBm}$, т.е. уровень сигнала превышает уровень шумов примерно в 1500 раз. Анализ показал, 

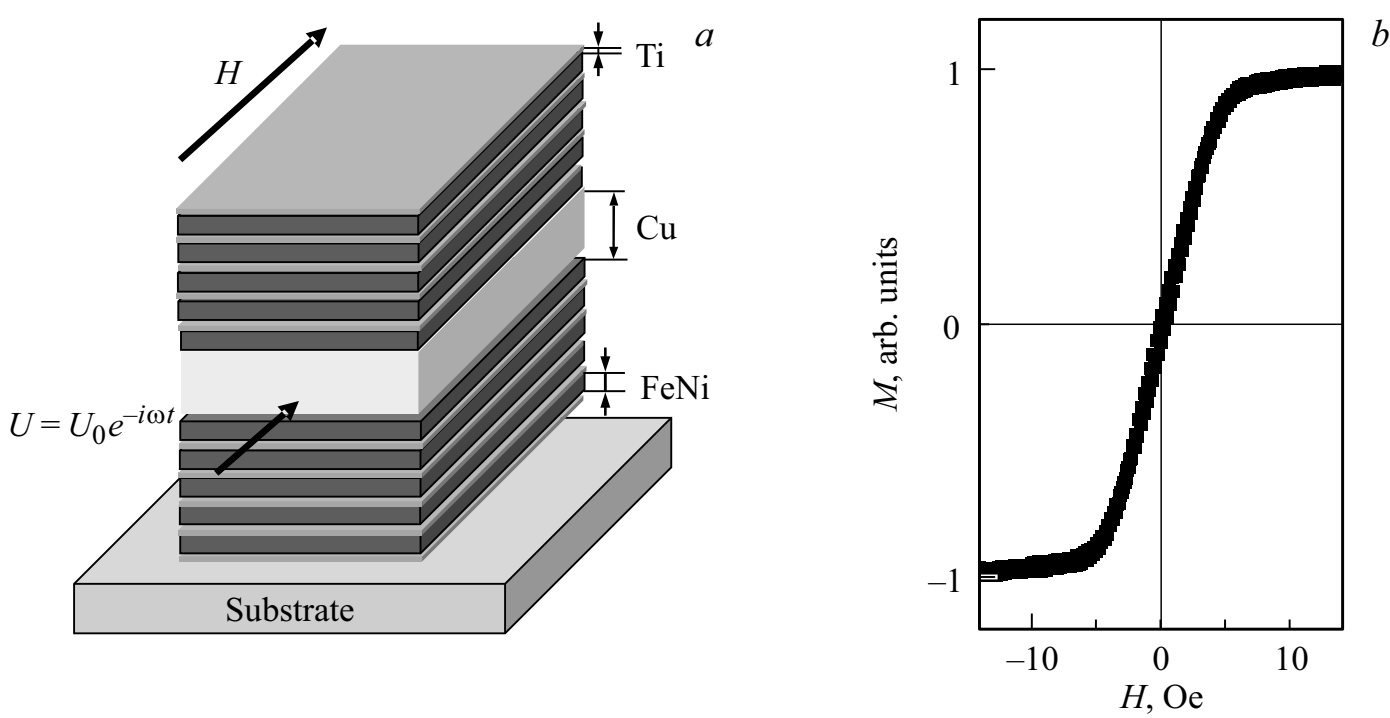

$b$

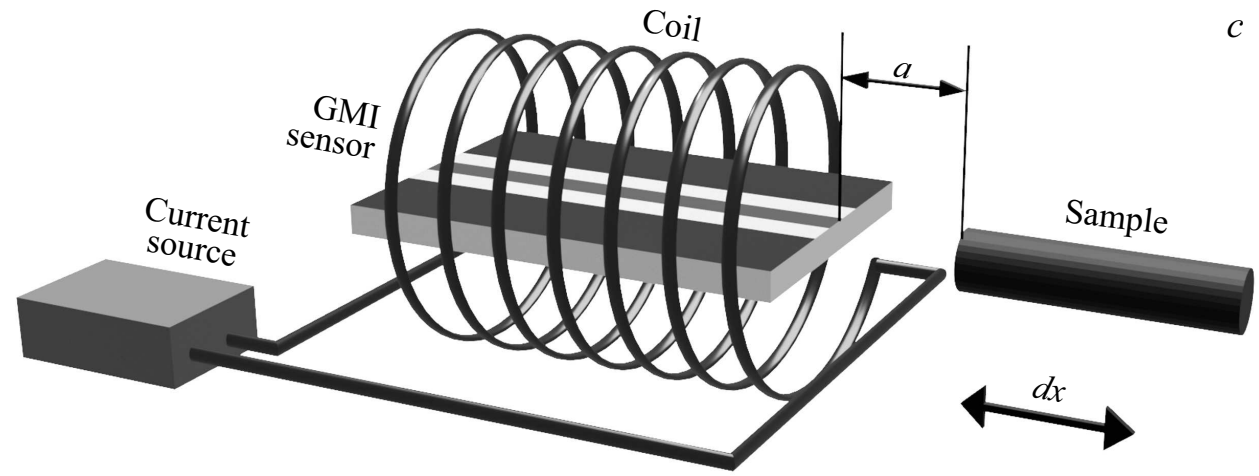

Рис. 9. Магнитное детектирование: $a)$ схематичное изображение многослойного пленочного ГМИ-элемента $[\mathrm{Ti} \mid \mathrm{FeNi}]_{5}|\mathrm{Ti}| \mathrm{Cu}|\mathrm{Ti}|[\mathrm{FeNi} \mid \mathrm{Ti}(6 \mathrm{~nm})]_{5}, H-$ внешнее магнитное поле, $U=U_{0} e^{-i \omega t}-$ переменное напряжение, $i-$ мнимая единица, $\omega-$ круговая частота, $t-$ время; $b$ ) магнитооптическая петля магнитного гистерезиса пленочного элемента при приложении внешнего поля вдоль длинной стороны элемента; $c$ ) схема проведения эксперимента по детектированию наночастиц оксида железа в образце композита (sample) с помощью автономного ГМИ-датчика ( $a$ - расстояние между краем ГМИ элемента и краем образца в виде цилиндра; $d x$ - направление смещения образца при тестировании).

что относительная погрешность измерений составляет $0.1 \%$, что соответствует классу точности прецизионного лабораторного оборудования. Это позволяет регистрировать магнитные поля на уровне сотен $\mu$ Ое. Для проведения экспериментов создана двухкоординатная система позиционирования с полем сканирования $20 \times 20 \mathrm{~cm}$, позволяющая перемещать датчик в соответствии с определенным алгоритмом.

На основе детектора слабых магнитных полей проведены исследования полей рассеяния композитов оксида железа в эпоксидной смоле. Образцы композитов длиной $30 \mathrm{~mm}$ и диаметром $4.85 \mathrm{~mm}$ (sample) с помощью системы позиционирования совершали колебания вдоль оси датчика слабых магнитных полей на основе многослойной ГМИ-пленки (GMI sensor) (рис. 8,c). Вдоль оси датчика колебания образцов осуществлялись с амплитудой $d x=2 \mathrm{~cm}$ (при этом частота колебаний композита составляла $1.10 \mathrm{~Hz}$ ) и с амплитудой $d x=4 \mathrm{~cm}$ (частота колебаний композита составляла $0.82 \mathrm{~Hz}$ ). При ампли- туде колебаний образцов от 2 до $4 \mathrm{~cm}$ на расстоянии $a=5 \mathrm{~mm}$ от датчика наблюдается устойчивый отклик детектора для концентраций магнетита в композитах от 70 до 9\%. При меньших концентрациях распознавание магнетита в композите невозможно, т. к. уровень сигнала находится на уровне шума. В качестве примера на рис. 10 представлены выходные сигналы АЦП-детектора $(U)$, записанные в режиме сканирования при детектировании магнитных полей рассеяния образцов с 50-процентным содержанием частиц магнетита.

Для более детального рассмотрения особенностей детектирования магнетита в составе композита проведен спектральный анализ полученных сигналов на основе преобразования Фурье. Амплитудную составляющую спектра обозначим как $|S(f)|$. Полученные спектрограммы при колебаниях образцов вдоль оси датчика представлены на рис. 10.

В результате нелинейной зависимости чувствительности ГМИ-датчика от расстояния до образца, синусои- 

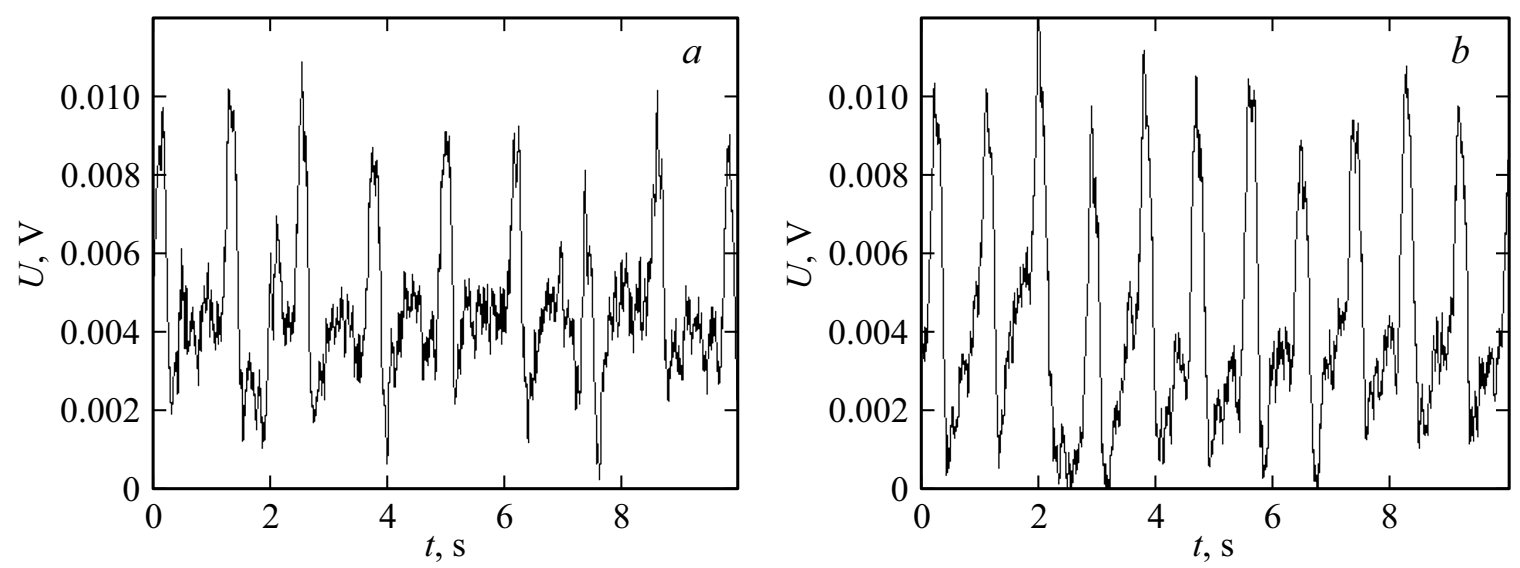

Рис. 10. Выходные сигналы детектора при сканировании композиционных образцов с содержанием частиц магнетита $50 \mathrm{wt} \%$ : a) сканирование с частотой $0.82 \mathrm{~Hz} ; b)$ сканирование с частотой $1.10 \mathrm{~Hz}$.
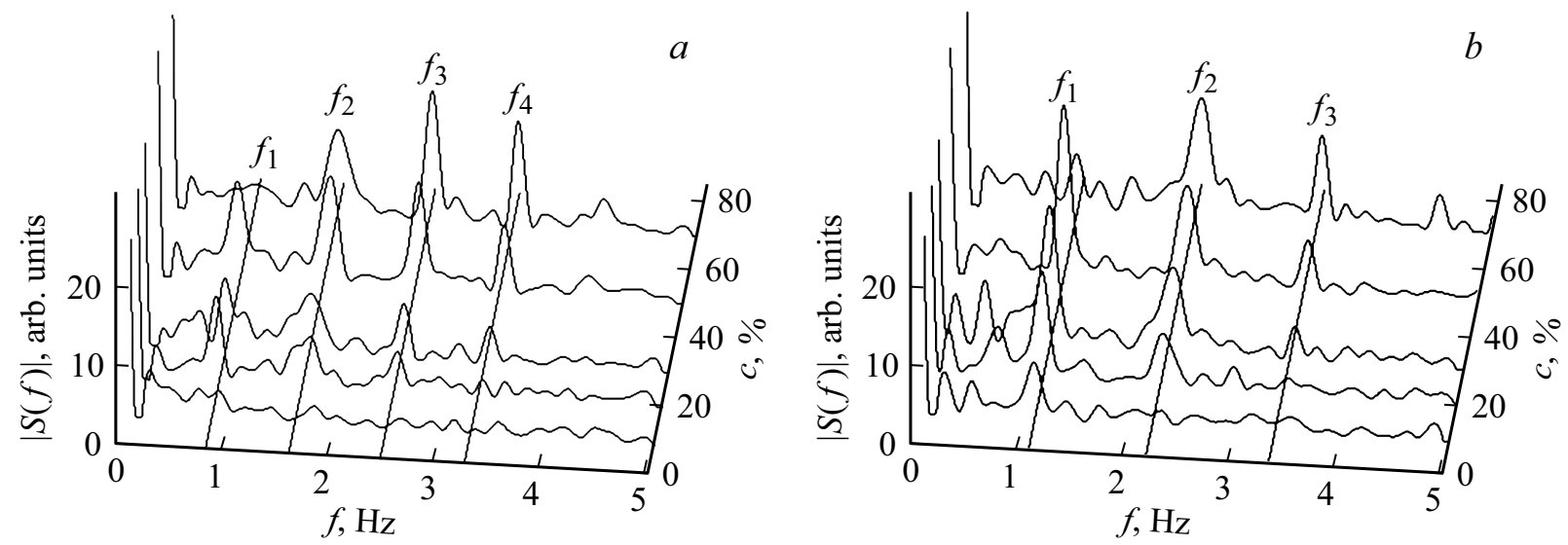

Рис. 11. Спектрограммы сигналов детектора при колебаниях образцов вдоль оси датчика: $a$ ) сканирование с частотой $0.82 \mathrm{~Hz}$ (частоты гармоник: $f_{1}=0.82 \mathrm{~Hz}, f_{2}=1.64 \mathrm{~Hz}, f_{3}=2.46 \mathrm{~Hz}, f_{4}=3.28 \mathrm{~Hz}$ ); $b$ ) сканирование с частотой $1.10 \mathrm{~Hz}$ (частоты гармоник: $\left.f_{1}=1.10 \mathrm{~Hz}, f_{2}=2.20 \mathrm{~Hz}, f_{3}=3.30 \mathrm{~Hz}\right)$.

дальная форма сигнала искажается, сигнал обогащается гармониками с частотами $2 f, 3 f, 4 f$ и т. д. Амплитуды гармоник сигнала в отдельных случаях могут превышать амплитуду основной гармоники $f_{1}$ (рис. 11). При этом вклад первой гармоники сигнала возрастает по сравнению с остальными гармониками с уменьшением концентрации магнетита в образцах (при снижении общего отклика) вплоть до уровня шума.

На основе данных, относящихся к выбранной гармонике (одной из гармоник выходного сигнала), получены концентрационные зависимости величины выбранного параметра от содержания МНЧ оксида железа в образцах композита. Пример зависимости амплитудного спектра второй гармоники $\left|S\left(f_{2}\right)\right|$ от концентрации $(c, \%)$ приведен на рис. 12. Данную зависимость можно аппроксимировать прямой линией, что позволяет судить о концентрации МНЧ в тестовых объектах по результатам измерений. Таким образом, разработанный детектор слабых магнитных полей позволяет распознавать маг-

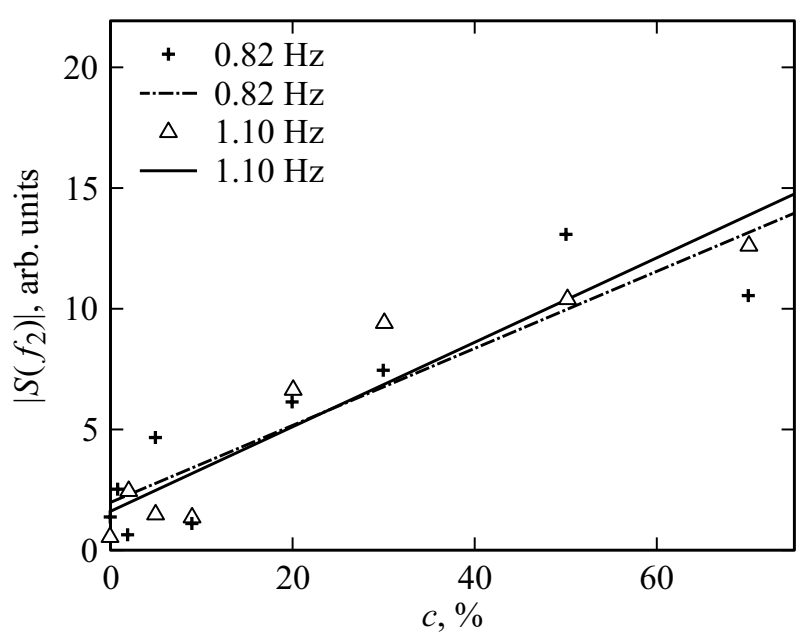

Рис. 12. Зависимость амплитуды 2-й гармоники сигнала автономного ГМИ детектора от концентрации оксида железа в образцах эпоксидных композитов. 
нитные наночастицы с концентрацией от 9 до 70\% в эпоксидном композите на расстоянии $1-4 \mathrm{~cm}$.

Для повышения чувствительности детектора можно, например, предложить процедуру с использованием методов оптимальной фильтрации, учитывающую вклад всех гармоник. Результаты экспериментов показывают, что пленочный ГМИ-детектор, работающий в автономном режиме, позволяет решать задачи магнитного детектирования на расстояниях порядка нескольких сантиметров.

\section{4. Заключение}

В работе были рассмотрены особенности получения МНЧ с помощью методов электрического взрыва проволоки, лазерного испарения мишени и искрового разряда: сферические ЭВП-МНЧ магнетита (средний размер после сепарирования около $15 \mathrm{~nm}$ ), сферические ЛИМ-МНЧ маггемита (средний размер после сепарирования около $10 \mathrm{~nm}$ ) и ИР-МНЧ магнетита (средний размер фракций сферической фракции около $7 \mathrm{~nm}$ и плоских частиц около 50-70 nm в их плоскости). Обсуждаются некоторые вопросы взаимодействия МНЧ с биологическими системами, возможность использования МНЧ и феррогелей на их основе в различных биоприложениях: в качестве субстратов в клеточных технологиях, при доставке лекарств, регенеративной медицине, а также как биомиметиков при создании магнитных биосенсоров.

\section{Благодарности}

Авторы благодарят А.М. Мурзакаева, А.И. Медведева, А.В. Багазеева, В.Н. Лепаловского, Т.П. Денисову, Н.А. Бузникова, И.А. Хлусова, Л.С. Литвинову, Ю.П. Новоселову, В.В. Щуплецову, Ф.А. Фадеева, А. Larrañaga, R. Andrade, A. Martínez-Amesti, S. Fernández-Armas за сотрудничество. Selected measurements were made at SGIKER services of UPV-EHU.

\section{Финансирование работы}

Работа выполнена при частичной поддержке Российского научного фонда (соглашение № 18-19-00090) и гранта MAT2017-83631-C3-R of the Spanish Government.

\section{Конфликт интересов}

Авторы заявляют, что у них нет конфликта интересов.

\section{Соблюдение этических стандартов}

Все применимые международные, национальные и/или институциональные принципы ухода и использования животных были соблюдены.

\section{Список литературы}

[1] Г.И. Фролов, О.И. Бачина, М.М. Завьялова, С.И. Равочкин. ЖТФ 78, 8, 101 (2008).

[2] R. Glaser. Biophysics. Springer Verlag, Heidelberg, Germany (1999). 362 p.

[3] Q.A. Pankhurst, A.J. Connolly, S.K. Jones, J. Dobson. J. Phys. D 36, 13, R167 (2003).

[4] A.G. Roca, R. Costo, A.F. Rebolledo, S. Veintemillas-Verdaguer, P. Tartaj, T. González-Carreño, M.P. Morales, C.J. Serna. Phys. D 42, 22, 224002 (2009).

[5] F. Spizzo, P. Sgarbossa, E. Sieni, A. Semenzato, F. Dughiero, M. Forzan, R. Bertani, L. Del Bianco. Nanomater. 7, 11, 373 (2017).

[6] Y.-W. Jun, J.-W. Seo, J. Cheon. Accounts. Chem. Res. 41, 2, 179 (2008)

[7] N. Singh, G.J.S. Jenkins, R. Asadi, S.H. Doak. Nano Rev. 1, 1, 5458 (2010).

[8] E.N. Maksimova, T.P. Denisova, E.V. Simonova, A.P. Safronov, V.I. Pedranova, I.N. Egorova, O.M. Samatov, G.V. Kurlyandskaya. Inorganic Materials: Appl. Res. 11, 4, 772 (2020).

[9] J.H. Grossman S.E. Mc Neil. Phys. Today 65, 8, 38 (2012).

[10] S.A.M. Khawja Ansari, E. Ficiara, F.A. Ruffinatti, I. Stura, M. Argenziano, O. Abollino, R. Cavalli, C. Guiot, F. D’Agata. Mater. 12, 3, 465 (2019).

[11] M.R. Zamani Kouhpanji, B.J.H. Stadler. Sensors 20, 9, 2554 (2020).

[12] D.R. Baselt, G.U. Lee, M. Natesan, S.W. Metzger, P.E. Sheehan, R.J. Colton. Biosens. Bioelectron. 13, 731 (1998).

[13] G.V. Kurlyandskaya, E. Fernandez, A.P. Safronov, A.V. Svalov, I.V. Beketov, A. Burgoa Beitia, A. García-Arribas, F.A. Blyakhman. Appl. Phys. Lett. 106, 19, 193702 (2015).

[14] F.A. Blyakhman, E.B. Makarova, F.A. Fadeyev, D.V. Lugovets, A.P. Safronov, P.A. Shabadrov, T.F. Shklyar, G.Yu. Melnikov, I. Orue, G.V. Kurlyandskaya. Nanomater. 9, 2, 232 (2019).

[15] N.A. Buznikov, A.P. Safronov, I. Orue, E.V. Golubeva, V.N. Lepalovskij, A.V. Svalov, A.A. Chlenova, G.V. Kurlyandskaya. Biosens. Bioelectron. 117, 366 (2018).

[16] Н.И. Енукашвили, И.Е. Коткас, Д.С. Боголюбов, А.В. Котова, И.О. Боголюбова, В.В. Багаева, К.А. Левчук, И.И. Масленникова, Д.А. Иволгин, А.Ю. Артамонов, Н.В. Марченко, И.В. Миндукшев. ЖТФ 90, 9, 1418 (2020).

[17] А.С. Камзин. ФТТ 58, 3, 519 (2016).

[18] S. Leulmi, X. Chauchet, M. Morcrette, G. Ortiz, H. Joisten, P. Sabon, T. Livache, Y. Hou, M. Carrière, S. Lequiena, B. Dieny. Nanoscale 7, 38, 15904 (2015).

[19] M. Goiriena-Goikoetxea, A. García-Arribas, M. Rouco, A.V. Svalov, J.M. Barandiaran. Nanotechnol. 27, 17, 175302 (2016).

[20] G.V. Kurlyandskaya, F.A. Blyakhman, E.B. Makarova, N.A. Buznikov, A.P. Safronov, F.A. Fadeyev, S.V. Shcherbinin, A.A. Chlenova. AIP Advances 10, 12, 125128 (2020).

[21] G.V. Kurlyandskaya, S.M. Bhagat, A.V. Bagazeev, A.I. Medvedev, A. Ballesteros, I.V. Beketov, A.P. Safronov. J. Phys. Chem. Solids 98, 255 (2016).

[22] Yu.A. Kotov. J. Nanopart. Res. 5, 5, 539 (2003).

[23] G.V. Kurlyandskaya, S.M. Bhagat, A.P. Safronov, I.V. Beketov, A. Larrañaga. AIP Advances 1, 4, 042122 (2011). 
[24] I.V. Beketov, A.P. Safronov, A.I. Medvedev, J. Alonso, G.V. Kurlyandskaya, S.M. Bhagat. AIP Advances 2, 2, 022154 (2012).

[25] A.P. Safronov, I.V. Beketov, S.V. Komogortsev, G.V. Kurlyandskaya, A.I. Medvedev, D.V. Leiman, A. Larrañaga, S.M. Bhagat. AIP Advances 3, 5, 052135 (2013).

[26] V.V. Osipov, V.V. Platonov, M.A. Uimin, A.V. Podkin. Tech. Phys. 57, 4, 543 (2012).

[27] G.V. Kurlyandskaya, D.S. Portnov, I.V. Beketov, A. Larrañaga, A.P. Safronov, I. Orue, A.I. Medvedev, A.A. Chlenova, M.B. Sanchez-Ilarduya, A. Martinez- Amesti, A.V. Svalov. Biochim. Biophys. Acta 1861, 6, 1494 (2017).

[28] C. Roth, G.A. Ferron, E. Karg, B. Lentner, G. Schumann, S. Takenaka, J. Heyder. Aerosol Sci. Technol. 38, 3, 228 (2004).

[29] http://www.iep.uran.ru/naudep/imppr/about/ (Последнее обращение 20.03.2021).

[30] F.A. Blyakhman, G.Y. Melnikov, E.B. Makarova, F.A. Fadeyev, D.V. Sedneva- Lugovets, P.A. Shabadrov, S.O. Volchkov, K.R. Mekhdieva, A.P. Safronov, S. Fernández Armas, G.V. Kurlyandskaya. Nanomater. 10, 9, 1697 (2020).

[31] S.O. Volchkov, A.V. Svalov, G.V. Kurlyandskaya. Russ. Phys. J. 52, 8, 769 (2009).

[32] A. Hubert, R. Schäfer. Magnetic Domains. Springer, Berlin, Germany (1998). 696 p.

[33] A.P. Safronov, G.V. Kurlyandskaya, A.A. Chlenova, M.V. Kuznetsov, D.N. Bazhin, I.V. Beketov, M.B. SanchezIlarduya, A. Martinez-Amesti. Langmuir 30, 11, 3243 (2014).

[34] А.А. Членова. Магнитные свойства и гигантский магнитный импеданс многослойных пленочных элементов на основе пермаллоя. Канд. дис. УрФУ (2020). 191 с.

[35] И.П. Шилов, В.Д. Румянцева, Ю.В. Алексеев, А.В. Иванов. Изв. РАН. Сер. физ. 84, 11, 1643 (2020).

[36] Н.П. Ивановская, И.П. Шилов, А.В. Иванов, В.Д. Румянцева, А.С. Горшкова. Рос. нанотехнологии 14, 5-6, 82 (2019).

[37] A. Shankar, A.P. Safronov, E.A. Mikhnevich, I.V. Beketov, G.V. Kurlyandskaya. Soft Matter 13, 18, 3359 (2017).

[38] A.P. Safronov, E.G. Kalinina, T.A. Smirnova, D.V. Leiman, A.V. Bagazeev. Russ. J. Phys. Chem. A 84, 12, 2122 (2010).

[39] G.V. Kurlyandskaya, I.P. Novoselova, V.V. Schupletsova, R. Andrade, N.A. Dunec, L.S. Litvinova, A.P. Safronov, R.F. Yurova, N.A. Kulesh, A.N. Dzyuman, I.A. Khlusov. J. Magn. Magn. Mater. 431, 249 (2017).

[40] J.P. Novoselova, A.P. Safronov, O.M. Samatov, I.V. Beketov, H. Khurshid, Z. Nemati, H. Srikanth, T.P. Denisova, R. Andrade, G.V. Kurlyandskaya. IEEE Trans. Magn. 50, 11, 4600504 (2014).

[41] M. Coïsson, G. Barrera, C. Appino, F. Celegatoa, L. Martino, A.P. Safronov, G.V. Kurlyandskaya, P. Tiberto. J. Magn. Magn. Mater. 473, 403 (2019).

[42] D.S. Portnov, I.V. Beketov, A. Larranaga, A. Martínez-Amesti, G.V. Kurlyandskaya. Vacuum 132, 1 (2016).

[43] M.D. Alcala, J.M. Criado, C. Real, T. Grygar, M. Nejezchleva, J. Subrt, E. Petrovsky. J. Mater. Sci. 39, 2365 (2004).

[44] F.A. Blyakhman, S.O. Volchkov, E.V. Golubeva, V.Y. Krokhalev, E.B. Makarova, K.R. Mekhdieva, A.P. Safronov, S.Y. Sokolov, F.A. Fadeyev, V.V. Chestukhin. Inorg. Mater.: Appl. Res. 11, 4, 766 (2020).

[45] F.A. Blyakhman, E.B. Makarova, P.A. Shabadrov, F.A. Fadeyev, T.F. Shklyar, A.P. Safronov, S.V. Komogortsev, G.V. Kurlyandskaya. Phys. Met. Metallogr. 121, 4, 299 (2020).
[46] F.A. Blyakhman, S.Yu. Sokolov, A.P. Safronov, O.A. Dinislamova, T.F. Shklyar, A.Yu. Zubarev, G.V. Kurlyandskaya. Sensors 19, 18, 3959 (2019).

[47] G.V. Kurlyandskaya, M.L. Sánchez, B. Hernando, V.M. Prida, P. Gorria, M. Tejedor. Appl. Phys. Lett. 82, 18, 3053 (2003).

[48] T. Wang, Y. Zhou, Ch. Lei, J. Luo, Sh. Xie, H. Pu. Biosens. Bioelectron. 90, 418 (2017).

[49] M. Coïsson, F. Vinal, P. Tiberto, F. Celegato. J. Magn. Magn. Mater. 321, 7, 806 (2009).

[50] A.V. Svalov, I.R. Aseguinolaza, A. Garcia-Arribas, I. Orue, J.M. Barandiaran, J. Alonso, M.L. Fernández-Gubieda, G.V. Kurlyandskaya. IEEE Trans. Magn. 46, 2, 333 (2010).

Редактор Е.В. Толстякова 